\title{
The efficiency of attentional networks in early and late bilinguals: the role of age of acquisition
}

\author{
Lily Tao ${ }^{1}$, Anna Marzecová ${ }^{2}$, Marcus Taft ${ }^{1}$, Dariusz Asanowicz ${ }^{2}$ and Zofia Wodniecka ${ }^{2 *}$ \\ School of Psychology, University of New South Wales, Sydney, NSW, Australia \\ 2 Institute of Psychology, Jagiellonian University, Krakow, Poland
}

Edited by:

Teresa Bajo, Universidad de Granada,

Spain

Reviewed by:

David William Green, University

College London, UK

Juan Lupiáñez, University of Granada,

Spain

*Correspondence:

Zofia Wodniecka, Institute of

Psychology, Jagiellonian University, Al.

Mickiewicza 3, Krakow, Poland.

e-mail:zofia.wodniecka@uj.edu.pl
Previous studies have demonstrated a bilingual advantage in the efficiency of executive attention. A question remains, however, about the impact of the age of $L 2$ acquisition and relative balance of the two languages on the enhancement of executive functions in bilinguals, and whether this is modulated by the similarity of the bilingual's two languages. The present study explores these issues by comparing the efficiency of attentional networks amongst three groups of young adults living in Australia: English monolinguals and early and late Chinese-English bilinguals. We also address the impact of bilingualism on hemispheric lateralization of cognitive functions, which is of interest since a recent study on early bilinguals revealed reduced hemispheric asymmetry in attentional functioning. In the present study, participants performed a modified version of the lateralized attention network test. Both early and late bilinguals were found to have more efficient executive network than monolinguals. The late bilinguals, who were also reported to be more balanced in the proficiency and usage of their two languages, showed the greatest advantage in conflict resolution, whereas early bilinguals seemed to show enhanced monitoring processes. These group differences were observed when controlling for non-verbal intelligence and socioeconomic status. Such results suggest that specific factors of language experience may differentially influence the mechanisms of cognitive control. Since the bilinguals had distinct language sets, it seems that the influence of bilingualism on executive functions is present regardless of the similarity between the two languages. As for hemispheric lateralization, although the results were not clear-cut, they suggest the reduced lateralization in early bilinguals.

Keywords: bilingualism, age of L2 acquisition, attentional networks, attention network test, lateralization

\section{INTRODUCTION}

A person who speaks two languages needs to attend to the language that is appropriate in the particular context and ignore the language that is irrelevant. This kind of experience may lead to development of more effective attentional mechanisms. Indeed, a substantive body of research has consistently shown benefits for bilinguals in some aspects of cognitive functioning, especially in executive control abilities (see Bialystok et al., 2009, for a review). The evidence for a bilingual advantage in tasks requiring resolution of conflict, or inhibition of non-relevant information, is consistent with the notion that bilinguals recruit the executive control system in order to manage the simultaneous activation of their two languages (Green, 1998; Abutalebi and Green, 2007; Kroll, 2008; van Heuven et al., 2008), as well as with the claim that the enhancement of such processes through continual practice may generalize to other domains of cognitive functioning (Bialystok et al., 2009; Ye and Zhou, 2009; Festman et al., 2010).

Although the impact of bilingualism on non-linguistic processes seems to be well-documented, many issues still remain open and there is a clear need to determine the boundaries of such influence. Hernandez et al. (2010) list two possible ways in which this goal may be achieved. The first is to identify the exact components of executive control that are modulated by bilingualism, and the second is to explore the extent to which bilingualism influences other aspects of attention. Both approaches seem to be of great importance since the relationship between bilingualism and executive functions appears to be more complex than initially claimed. Research practice shows that some of the effects indicating cognitive benefits in bilinguals are not always easy to replicate (cf. Bialystok et al., 2005b; Colzato et al., 2008), and the detectability of the bilingual advantage in conflict resolution may be limited to some specific experimental conditions (Colzato et al., 2008; Costa et al., 2009). Moreover, in order to fully understand the nature of the relationship between bilingualism and the reported cognitive gains, we also need to explore which aspects of bilingual experience are crucial for the effect to emerge (Kroll, 2009).

Factors that can potentially contribute to the emergence of the bilingual benefit include the speaker's language proficiency and relative balance between the two languages, the intensity of daily usage of each of the two languages, length of exposure, age of L2 acquisition, the degree of similarity between a bilingual's two languages, and specificities related to the context in which both languages are being used on a daily bases. The latter relates to whether the two languages are separated in time in daily use (one language at home, the other at work), or whether daily usage involves frequent mixing of languages. According to Costa et al. (2009), this sociolinguistic factor may impact on whether bilinguals show enhancement of the monitoring aspect of executive functions. Disentanglement of how each of the factors selectively contributes 
to the cognitive benefit is a challenging task. Let us consider briefly how two of the factors listed above may contribute to changes in attentional control in bilinguals.

\section{SIMILARITY BETWEEN LANGUAGES}

Although bilingual benefits in executive functions in children and the elderly have been replicated across different languages and cultural contexts, reports on similar advantages in young adults are scarce and so far limited to bilinguals with language sets that are relatively similar in terms of lexical and grammatical structure (mostly Catalan-Spanish; Costa et al., 2008, 2009; Hernandez et al., 2010; but see Bialystok et al., 2005a; see also Table 1 for a review). It may therefore be that usage of two typologically similar languages requires a greater degree of attentional control, leading to more efficient executive and alerting networks. It remains an open question whether having two structurally distinct language sets will lead to similar advantages in young adults who are at the peak of their cognitive abilities. Costa et al. (2008) suggested that the need to monitor the two languages may be particularly strong in contexts in which bilinguals use their two languages interchangeably (such as Catalan-Spanish speakers in Barcelona) and less needed in the case of bilinguals who have a clear separation between the languages and daily activities.

\section{AGE OF ACQUISITION}

Does one need to be an early bilingual to enjoy the benefits of improved executive functions? Indeed, most research reporting cognitive gains in bilinguals examined bilinguals who learnt their two languages relatively early in life (see Table 1). The only two exceptions so far are studies by Bialystok et al. (2006) and Wodniecka et al. (2010). However, in both of these studies, the late bilinguals represented elderly participant groups. Does it mean that, at least for young adults, early age of L2 acquisition is necessary for the attentional benefit to emerge? If not, what are the critical conditions that must be fulfilled by late bilinguals to confer similar advantages? Age of acquisition might have an influence on bilinguals' efficiency in executive control not necessarily because of biological or maturational constraints on language learning, but because of a set of environmental factors that might be the consequence of early or late L2 learning. In the most obvious way, age of acquisition has an impact on (although it does not determine) the amount of input that one receives in each language. If the length of simultaneous exposure to two languages is critical for the cognitive advantage to emerge, then early bilinguals should naturally enjoy greater cognitive benefits than late bilinguals. On the other hand, there are grounds to suggest that late bilinguals may, in fact, train their executive control to a greater extent than early bilinguals and hence display a larger cognitive benefit related to the training. Abutalebi and Green (2007) demonstrated that bilingual language production engages the neural executive network to a greater extent than monolingual production, suggesting the importance of the network in selecting a language in the face of interference. Moreover, L2 processing is more effortful than L1 processing and involves more extensive activation in the left frontal region than processing of the same language by monolingual speakers (Wartenburger et al., 2003; Hernandez and Meschyan, 2006; Abutalebi, 2008; Kovelman et al., 2008). This seems to suggest that late bilinguals utilize the executive network to a greater extent than early proficient bilinguals, presumably because executive control not only helps them control interference from their other language, but also supports processing of the less automatic L2. A model developed by Hernandez et al. (2005) proposes that $\mathrm{L} 2$ learning involves a competitive interplay between a bilingual's two languages in which speakers must overcome interference from L1. The more solidified that L1 is, the more difficult L2 learning becomes. It seems plausible then that, although bilingualism may result in massive training of the executive network, late bilinguals are even more prone to this training due to greater interference of L1 during L2 learning.

Previous research has reported bilingual advantages in children and older adults, which are the two groups whose attentional capacities are either not fully developed or are in decline. The first study that demonstrated the effect of bilingualism on executive control in young adults in their twenties was carried out by Costa et al. (2008). The authors used the attention network test (ANT; originally developed by Fan et al., 2002) to compare the efficiency of three attentional networks in Catalan-Spanish bilinguals and Spanish monolinguals: alerting, orienting, and executive control. Attentional networks are a system of functionally and neuro-anatomically independent webs of neural areas, which are involved in three kinds of functions: achieving and maintaining an alert state, orienting to sensory or mental events, and monitoring and resolving competitions or conflicts (Raz and Buhle, 2006; Posner and Rothbart, 2007; Posner and Fan, 2008). Costa et al. (2008) found young adult bilinguals to be advantaged in conflict resolution. Moreover, bilinguals showed a larger alerting effect, but did not differ from monolinguals in their orienting of attention. In addition, bilinguals were overall faster than monolinguals in performing the task. In their subsequent ANT study with young adult bilinguals, Costa et al. (2009) argued that the overall reaction time (RT) advantage of bilinguals may indicate higher efficiency of the monitoring system, which evaluates the need to engage in conflict resolution processes. How exactly the monitoring and the conflict resolution processes interact with each other and to what extent they depend on one another is still an open issue (cf. Costa et al., 2009). Nevertheless, the available evidence suggests that bilingualism may impact various aspects of the cognitive control mechanism. A recent study by Marzecová, Asanowicz, Krivá, and Wodniecka (submitted for publication) replicated the results obtained by Costa et al. (2008) in relation to executive and alerting networks. However no overall advantage in RTs was observed. The results of Marzecová et al. (submitted for publication) suggest an advantage for bilinguals in conflict resolution per se, but not in the process of monitoring (cf. Costa et al., 2009). The participants in that study were early, relatively balanced speakers of two languages that are typologically similar to each other (mostly Czech-Slovak bilinguals). The participants tested in all three studies described above represented similar profiles: They were early bilinguals with life-long exposure to the two typologically similar languages. It is therefore impossible to determine which aspect of their experience was crucial for the attentional advantage that was observed. An important question stemming from previous research with the ANT task, then, is whether similar effects would be observed in a group of bilinguals whose two languages are more distinct from each other, and if so how the later age of acquisition would impact on the pattern of results. 


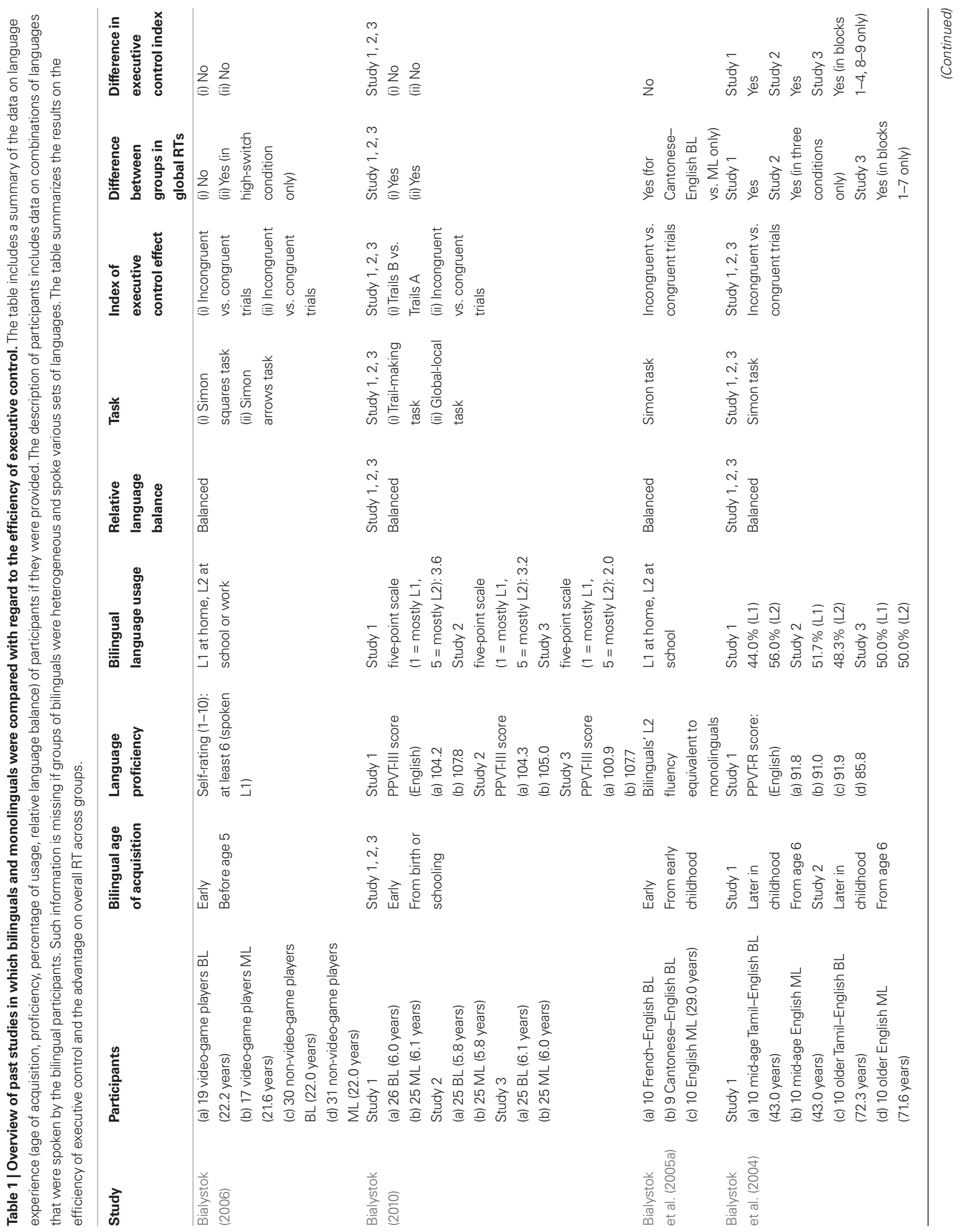




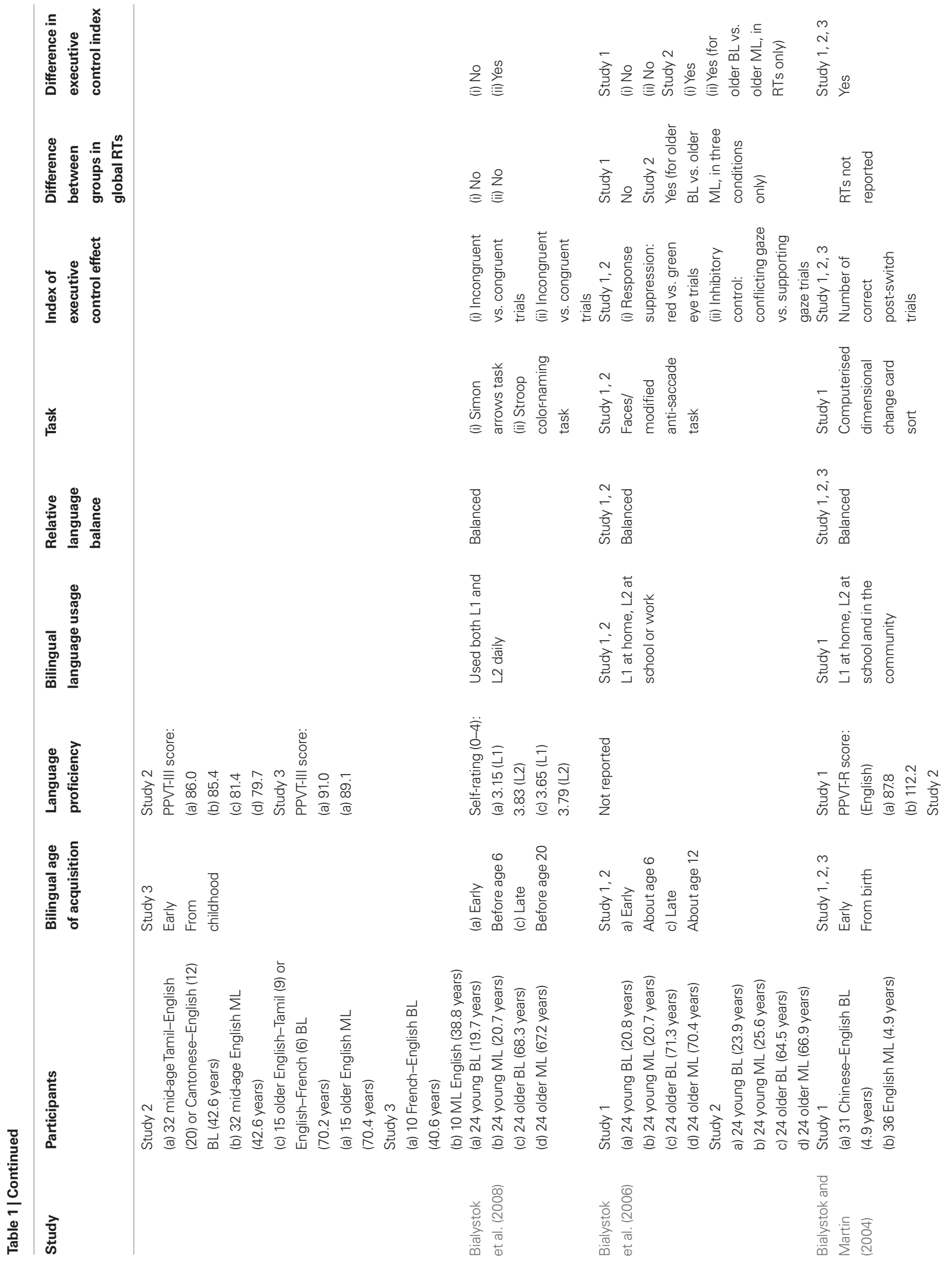




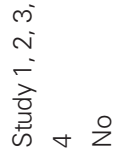

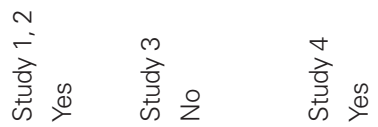

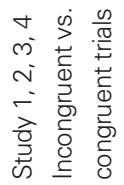

吕总

慈兽

울

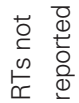

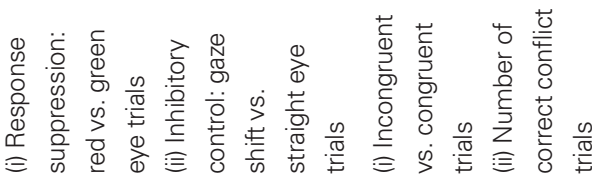

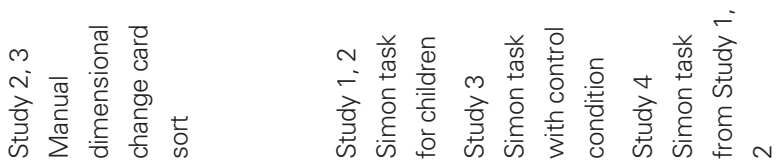

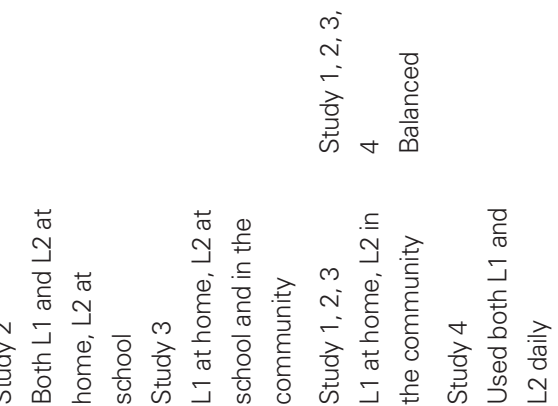

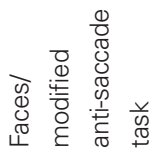

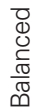

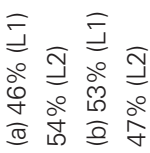

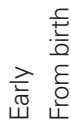

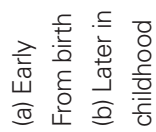

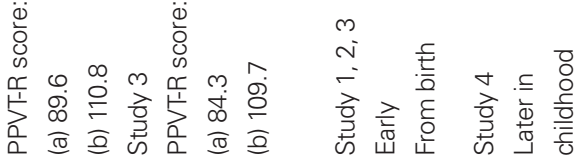

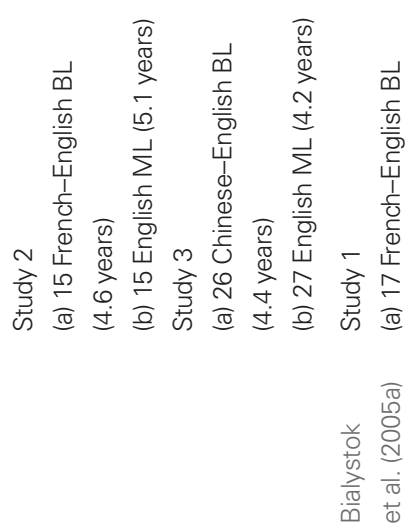

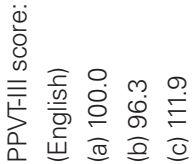

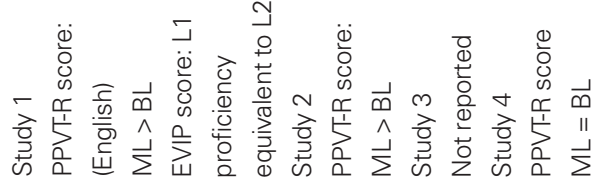

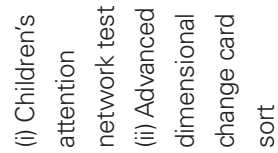

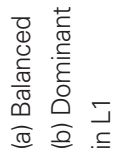

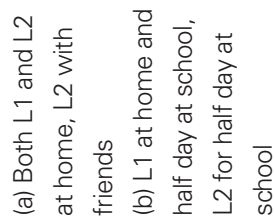




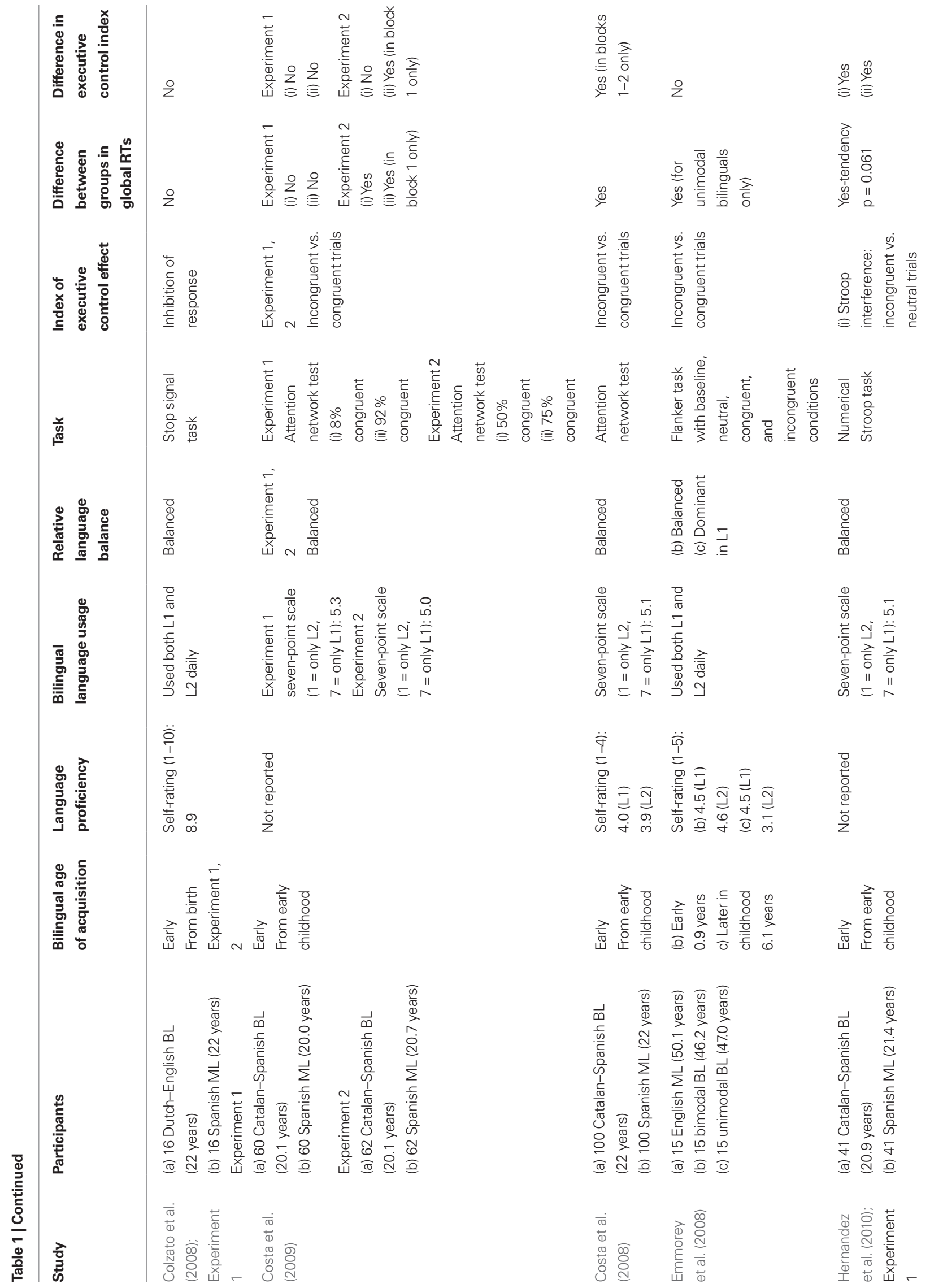




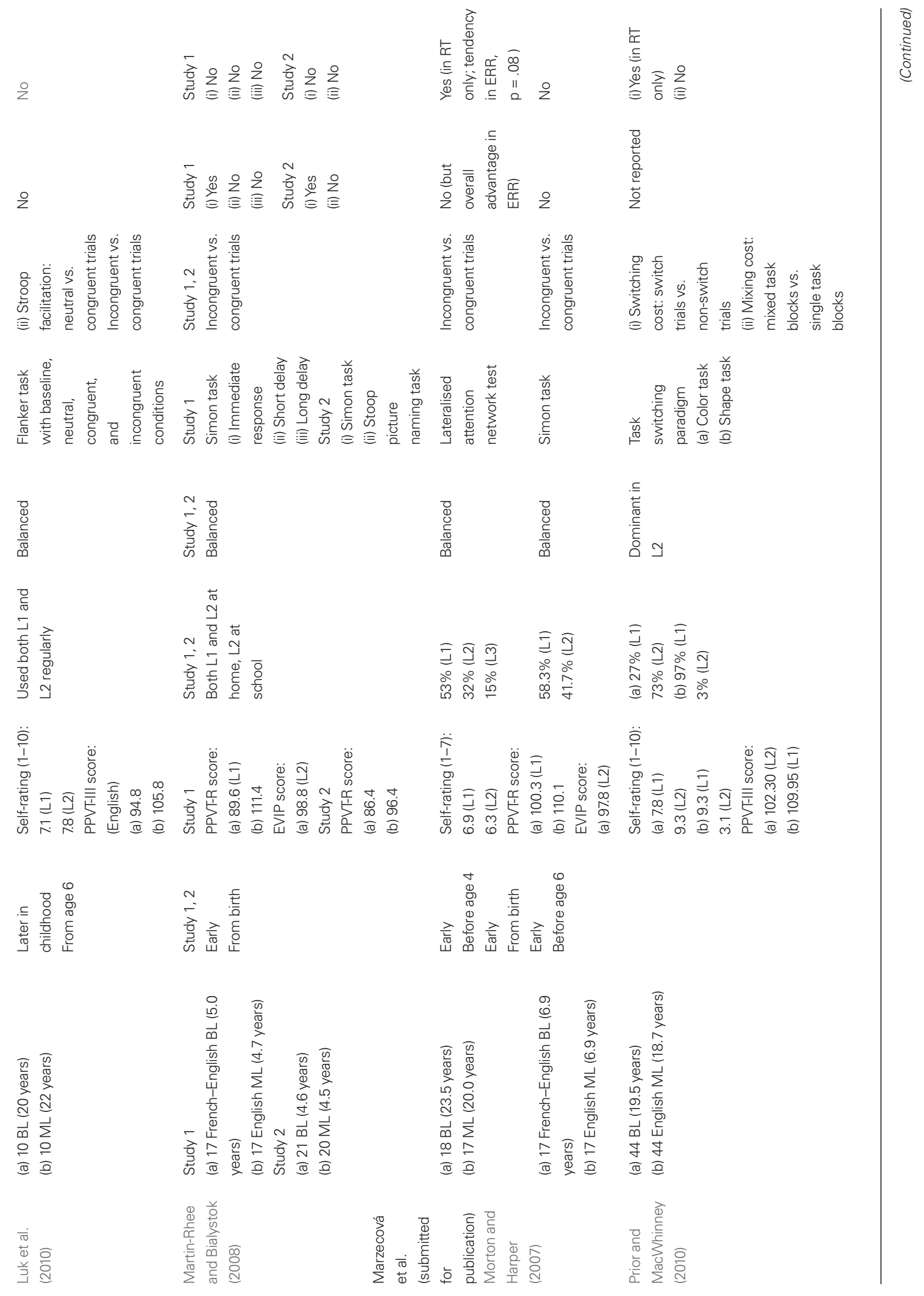




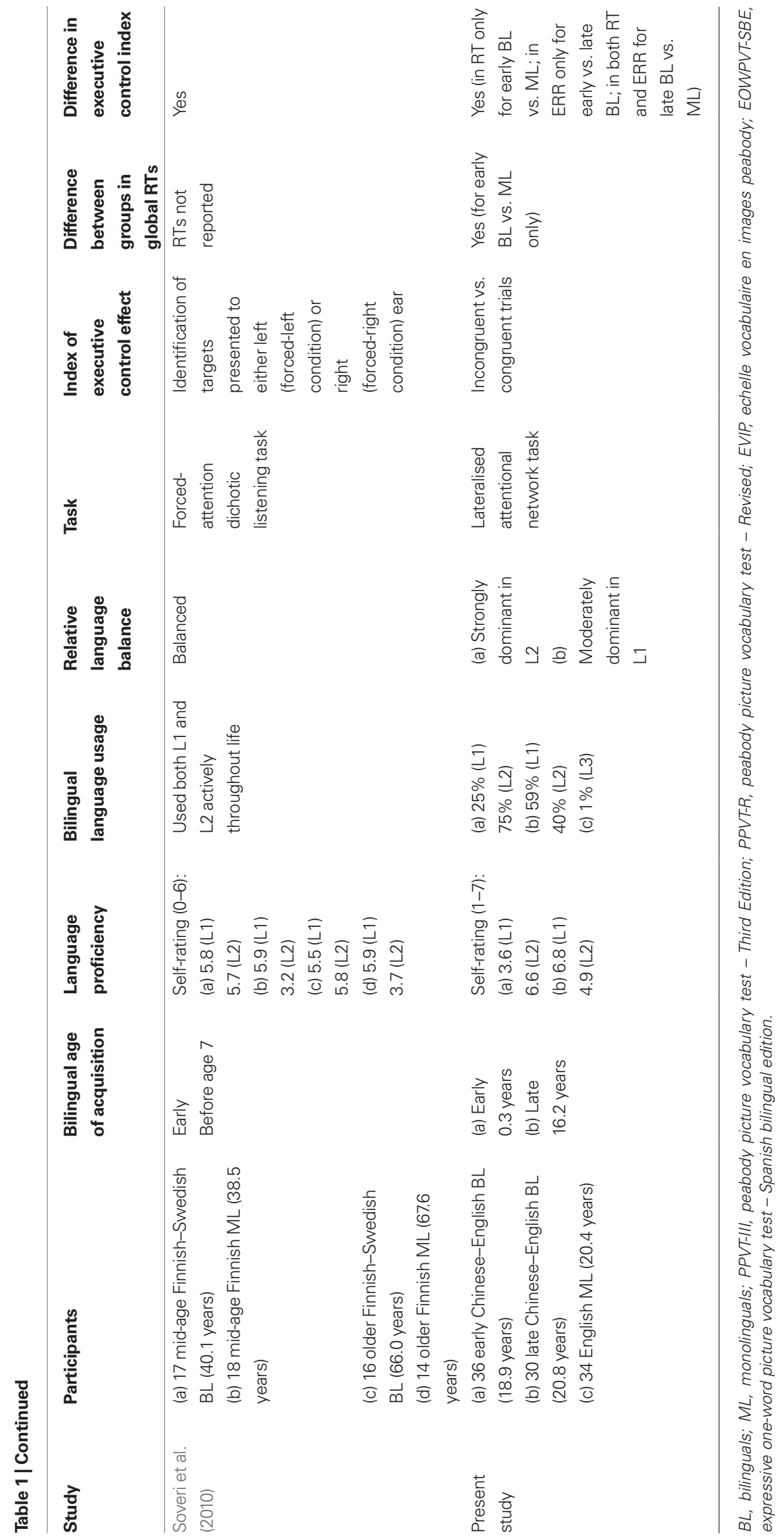


The present study aimed at comparing early and late bilinguals in the efficiency of the three attentional networks, alerting, orienting, and executive control (cf. Posner and Rothbart, 2007; Posner and Fan, 2008), and thus to shed some light on the interaction between age of L2 acquisition and cognitive gains associated with bilingualism. We asked which aspects of attentional functions are modulated by early and late bilingualism and to what extent the L2 age of acquisition has a differential impact on attention. We aimed at extending earlier findings on attentional advantage observed in early young bilinguals by including a group of late bilinguals, who acquired L2 in their adolescent years. Additionally, the bilinguals in the current study were a linguistically homogeneous group whose two languages were very distinct from each other; namely, Chinese and English. This allowed for comparison between the results from the current study with earlier research with bilinguals who spoke two very similar languages.

An alphabetic language like English has a phonemically based script, which is a system of letters that each represents a unit of sound (phoneme). The Chinese language, in contrast, has a morphosyllabic script, which is a system of characters each representing a unit of semantic meaning (morpheme) and having little systematic correspondence to phonology. In order to vocalize and comprehend Chinese, one must memorize the phonology and meaning of each character (Chee et al., 1999; Luk and Bialystok, 2008). Further, neuroimaging evidence suggests that different cognitive and processing resources may be required for reading and understanding Chinese as opposed to English (e.g., Tan et al., 2003), which may result in a lesser conflict between the two languages. If the advantage of bilingualism is related to the two language systems being similar to each other, then the Chinese-English bilinguals, both early and late, would show no advantage over monolinguals in the functioning of attentional networks. On the other hand, if the typological distance between the two languages of a bilingual does not play a role, then the early Chinese-English bilinguals may show advantages in alerting and executive networks, corroborating previous findings with language sets that are more similar to each other (Costa et al., 2008; Marzecová et al., submitted for publication). Such a finding would reveal that bilingual experience influences attentional functioning irrespective of the degree of similarity between languages, and would be consistent with previous studies on Chinese-English bilingual children (Goetz, 2003; Bialystok and Martin, 2004). If advantages in attentional functioning were to be found in early Chinese-English bilinguals, late bilinguals may or may not show similar pattern. If the constant practice in monitoring and switching between languages since an early age is necessary to gain enhancement of attentional functioning, then it may not be observed in late bilinguals. If, however, late bilinguals train the executive network more intensively than early bilinguals (because they need to control interference from L1, which may be even greater than in early bilinguals, as well as to support the less automatized L2; Costa et al., 2009), then the late Chinese-English bilinguals may show even more enhanced efficiency of attention than early bilinguals, especially in conflict resolution processes.

Besides exploring the impact of bilingual experience on attentional networks, we sought to investigate pattern of lateralization in bilinguals' attentional functioning. The lateralization of attention in bilinguals was of interest since previous research indicated that bilingualism may modulate interhemispheric organization of the attentional networks, especially with regard to executive control (Marzecová et al., submitted for publication). To assess hemispheric asymmetries of three attentional networks (alerting, orienting, and executive control), we employed a lateralized attention network test (LANT; Greene et al., 2008). Reduced hemispheric asymmetry in bilinguals has previously been reported for language functions (Dehaene et al., 1997; Moreno et al., 2010), but also for non-verbal cognitive functions (Hausmann et al., 2004). Moreover, the study by Marzecová et al. (submitted for publication) showed right hemisphere dominance for conflict resolution in monolinguals, and a lack of such asymmetry in bilinguals. Both studies that reported the lack of hemispheric asymmetry tested early bilinguals (Hausmann et al., 2004; Marzecová et al., submitted for publication). It remains an open question, then, whether late onset bilinguals display a similar pattern of lateralization for non-linguistic functions as early bilinguals. The hemispheric asymmetry of linguistic processes appears to be influenced by the age of acquisition of the second language. Meta-analyses of language studies (Hull and Vaid, 2006,2007 ) indicate that, regardless of proficiency, bilinguals who acquired their second language at an early age (typically before age six) consistently show more bilateral involvement in linguistic tasks for both L1 and L2. Late bilinguals, on the other hand, exhibit left hemispheric lateralization for both their languages, as is typically observed in monolinguals. Analogously, it is possible that early bilinguals would show reduced hemispheric asymmetry of attentional networks, while late bilinguals would show the same pattern of lateralization as monolinguals. If this is the case, it may be argued that early experience in learning a second language is critical in altering the functional cerebral organization of non-linguistic functioning.

\section{MATERIALS AND METHODS MATERIALS AND PROCEDURE Background questionnaire}

A language background questionnaire was used to obtain participant information in order to classify the bilinguals as either Early or Late. Demographics details were also collected to allow any major differences between groups, such as age, gender, and socioeconomic background, to be identified. In particular, lower socioeconomic status (SES) has been shown to be associated with deficits in aspects of attention, especially in tasks that require filtering information and managing response conflict (see e.g., Stevens et al., 2009). In the present study, parental occupation was used as an index of SES. Following the recommendations of McMillan (2010), specific occupations of the mother and father were coded using the Australian and New Zealand Standard Classification of Occupations (ANZSCO; Australia Bureau of Statistics/Statistics New Zealand, 2009), and then converted into a percentile score using the Australian Socioeconomic Index 2006 (AUSEI06; McMillan et al., 2009). The higher of the two parents' scores was retained as the SES score for each participant. Parental education level, determined as the average of the two parents' number of years of education, provided further information about socioeconomic background, as parental education is a good predictor of SES (see Marks et al., 2000).

In addition to sociodemographic details, bilingual participants provided information relating to language experience, so that effects of individual differences in factors such as proficiency 
and usage could be examined. Bilinguals rated their proficiency in both Chinese and English, separately for speaking, understanding speech, reading, and writing, using a seven-point scale ( $1=$ Not at all; $7=$ Native-like). Self-ratings were also provided for the amount of daily usage of each language (expressed in percentages), the frequency of mixing their two languages in the same sentence, on a five-point scale ( 1 = Rarely; 5 = Very frequently), and the frequency of deliberately refraining from uttering a Chinese word or phrase when speaking to an English speaker, on a fivepoint scale ( 1 = Rarely; 5 = Very frequently). The latter two selfratings allowed differences in frequency of mixing and inhibiting to be examined. The questions pertaining to language experience were mostly adapted from questions in the L2 Language History Questionnaire (Li et al., 2006) and the Language Dominance Scale (Dunn and Fox Tree, 2009).

Lastly, the handedness of participants was established using a question adapted from the Edinburgh Handedness Inventory (Oldfield, 1971). Participants indicated whether they used their left hand for any of a list of eight activities. People who marked four or more activities were deemed to be left-handed.

\section{Non-verbal intelligence test}

In order to compare general non-verbal intelligence across the three groups, participants completed a shortened version of Raven's Advanced Progressive Matrices Set I (Raven et al., 1998). One point was given for each correct answer, with a maximum total of 12 ; the total score was used as an index of the person's general non-verbal intelligence.

\section{Lateralized attention network test}

The LANT is a computer-based task requiring manual responses to stimuli presented on screen. Stimuli were presented using the DMDX program (Forster and Forster, 2003). The main stimulus in the LANT comprised an array of five arrows, oriented and arranged in a vertical line. The middle arrow was the target and either pointed up or down. The target was flanked with other arrows that were either congruent, i.e., pointing in the same direction as the target; or incongruent, i.e., pointing in the opposite direction (see Figure 1A). The array of arrows subtended a height of $3.0^{\circ}$ visual angle, and was presented at a distance of $2.2^{\circ}$ visual angle from a central fixation cross to either left or right visual field. The stimuli were preceded by one of four types of cue: (i) a valid spatial cue, which was an asterisk presented in the same visual hemifield as the target; (ii) an invalid spatial cue, which was an asterisk presented in the opposite visual hemifield; (iii) a center cue, which was an asterisk presented at the location of the fixation cross; and (iv) no cue (see Figure 1B). For the spatial cue conditions, $80 \%$ were valid while the other $20 \%$ were invalid. The LANT procedure and stimuli parameters were based on the study by Greene et al. (2008).

Each trial of the LANT consisted of five events as follows: (i) a central fixation cross presented for a period of random variable duration (1300-2700 ms), ensuring that the onset of the target stimuli was predicted by the cue and not by the regular timing of the initial fixation period; (ii) a cue presented for $100 \mathrm{~ms}$; (iii) a short fixation period for $400 \mathrm{~ms}$; (iv) the target and flanker stimuli flashed randomly to either left or right of the fixation cross for $180 \mathrm{~ms}$, in order to isolate the information to one hemisphere;

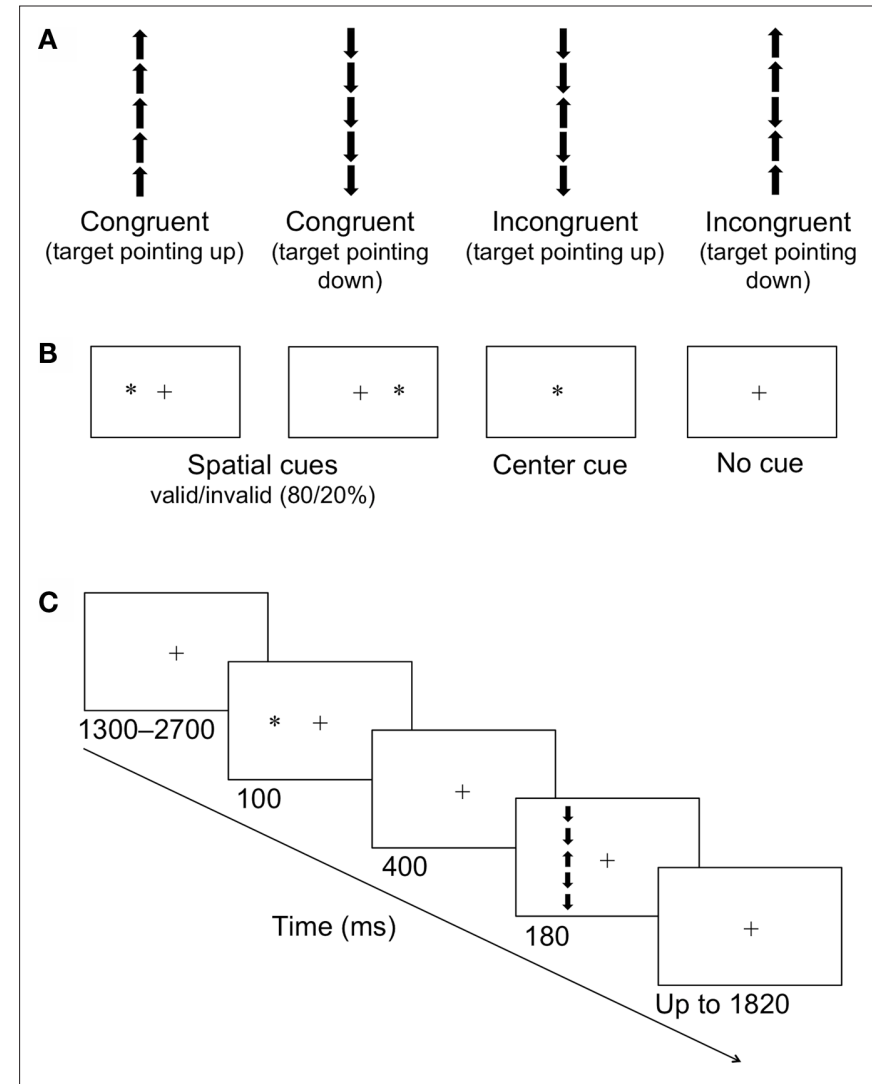

FIGURE 1 | Schematic representation of targets and flankers (A), types of cues (B), and events in the lateralized attention network test [LANT (C)].

and (v) a response period that ended once participants responded, or timed out after $1820 \mathrm{~ms}$ (see Figure 1C). The fixation cross remained on the screen throughout whole trial, until participants responded or the trial timed out. During the task, a chin rest with forehead bar was used to secure the position of the eyes of participants at a distance of $50 \mathrm{~cm}$ away from the center of the screen. Participants were instructed to keep their heads still and fixate on the central cross throughout the session. Their task was to respond as accurately and as quickly as possible to the direction of the target middle arrow, ignoring the four flanker arrows. First there were two 12-trial practice blocks, in which participants received feedback for the accuracy of response for each trial. Two experimental blocks then followed, each consisting of 144 trials. Within each block, trials were presented in a randomized order. The number of trials was divided equally across the two flanker types, as well as across the two visual hemifields. Responses were made on a mouse held sideways, so that the two buttons were oriented vertically. Response hand alternated between blocks in a counterbalanced order across participants.

The LANT provides indices for the efficiency of alerting, orienting, and executive networks (cf. Fan et al., 2002). Subtracting RT or accuracy in the center cue condition from no cue condition allows the efficiency of the alerting network to be measured. Typically, performance is much improved after occurrence of the center (warning) cue, which signals when target will appear next (Posner, 2008). Comparison between the results in a valid spatial 
cue condition (which informs participants where the target will occur) and the results in a center cue condition provide information about the efficiency of orienting to the target location. If a target is preceded by a valid spatial cue, responses are faster and more accurate, since attention is already focused on the target location (Posner, 1980). Additionally, orienting cost can be examined by comparing an invalid spatial cue condition with a center cue condition. The orienting cost reflects the efficiency of reorienting to the target presented outside the current focus of attention (Corbetta et al., 2008). Finally, a comparison between congruent and incongruent flanker conditions shows the cost of conflict resolution, which is an index of the executive network's efficiency. In order to respond quickly and accurately to a target in the incongruent condition one must inhibit the interference and resolve the conflict caused by flankers, which are incongruent with the target (Eriksen and Eriksen, 1974; Fan et al., 2003).

\section{PARTICIPANTS}

A total of 100 people participated in this study, each belonging to one of three groups: Early Bilinguals $(n=36)$, Late Bilinguals $(n=30)$, and Monolinguals $(n=34)$. Overall, the age of participants ranged from 18 to 48 years $(M=20.0, \mathrm{SD}=3.7)$; there were 56 females and 44 males. The participants were students undertaking a first year psychology course at the University of New South Wales, who received course credit in exchange for participation. The study was approved by the Human Research Ethics Advisory Panel of the School of Psychology at the UNSW and participants provided written informed consent prior to participation.

No left-handed participants were tested, as patterns of cerebral lateralization have been found to vary more in left-handers (Andreou and Karapetsas, 2001). The Chinese-English bilingual groups included both Mandarin and Cantonese speakers, as there is essentially no difference in structure between these two dialects. The age of arrival to Australia (or to another English-speaking country) was considered as the age of L2 exposure, thus the age of immersion in the L2 environment was considered as the age of onset of bilingualism and used in the classification of bilinguals as either Early or Late. Table 2 presents the sociodemographic characteristics for the three groups, along with their Raven's non-verbal intelligence scores. The language characteristics of the two bilingual groups are also presented.

\section{Monolinguals}

All of the participants in the Monolingual group were born, and had spent most of their lives, in Australia or other English-speaking countries. All were of Caucasian descent. People whose parents spoke other languages were excluded, as they may have had some understanding and/or ability to communicate in a second language.

\section{Early bilinguals}

The Early Bilingual group consisted of those who had arrived in Australia at or before age six. The average age of arrival for the group was 0.3 years, due to the large majority (30) being born in Australia (i.e., age of arrival 0 years). For the six who were not born in Australia, the average age of arrival was 2.1 years. Given the average ages of first learning English and first being able to communicate in English (see Table 2), it can be assumed that most of
Table 2 | Characteristics of participant groups (SD in parentheses).

\begin{tabular}{llll}
\hline & \multicolumn{3}{c}{ Group } \\
\cline { 2 - 4 } Characteristic & Early & Late & Mono \\
\hline Age & $18.9(1.3)$ & $20.8(2.5)$ & $20.4(5.5)$ \\
Gender (F:M) & $19: 17$ & $19: 11$ & $18: 16$ \\
$\begin{array}{l}\text { Socioeconomic status } \\
\text { (percentile score) }\end{array}$ & $48.6(24.2)$ & $62.3(21.3)$ & $77.3(17.0)$ \\
Parental education (years) & $11.8(3.7)$ & $13.7(3.4)$ & $14.7(3.2)$ \\
Non-verbal intelligence & $9.1(2.3)$ & $8.2(3.0)$ & $6.9(3.0)$ \\
score (out of 12) & & & \\
Age of first learning L2 & $2.9(1.8)$ & $7.8(3.7)$ & - \\
Age of first able to & $4.0(1.7)$ & $12.3(4.7)$ & -
\end{tabular}

communicate in $\mathrm{L} 2$

$\begin{array}{lcl}\text { PROFICIENCY IN L1 (SEVEN-POINT SCALE) } & \\ \text { Speaking } & 4.9(0.9) & 6.7(0.7) \\ \text { Understanding } & 5.2(1.0) & 6.7(0.6) \\ \text { Reading } & 2.4(1.2) & 6.6(0.7) \\ \text { Writing } & 2.1(1.1) & 6.3(0.9)\end{array}$

PROFICIENCY IN L2 (SEVEN-POINT SCALE)

$\begin{array}{llll}\text { Speaking } & 6.8(0.4) & 4.9(1.0) & - \\ \text { Understanding } & 6.9(0.3) & 5.0(0.9) & \\ \text { Reading } & 6.8(0.4) & 5.1(0.9) & \\ \text { Writing } & 6.7(0.6) & 4.7(0.9) & \\ \text { Percentage use of L1 and } & 25: 75 & 59: 40 & - \\ \text { L2 (L1:L2) } & & & \\ \begin{array}{l}\text { Frequency of mixing L1 and } \\ \text { L2 (five-point scale) }\end{array} & 3.0(1.4) & 3.4(1.0) & - \\ \begin{array}{l}\text { Frequency of inhibiting L1 } \\ \text { (five-point scale) }\end{array} & 1.6(1.1) & 2.1(1.2) & - \\ \end{array}$

Early = early bilinguals; late = late bilinguals; mono = monolinguals .

the Early Bilinguals learned Chinese as their first language. Nearly all (32) of the participants in this group indicated a higher level of proficiency for English compared to Chinese, and a higher percentage of daily use of English over Chinese. Every Early Bilingual had received all of their formal education in English.

\section{Late bilinguals}

The Late Bilingual group consisted of those who had arrived in Australia at or after age 12. The average age of arrival in Australia for the group was 16.2 years (ranging from 12 to 19 years). As can be seen in Table 2, the Late Bilinguals first learned and were first able to communicate in English at substantially later ages than Early Bilinguals. Further, in contrast to the Early Bilinguals, the majority (24) of the Late Bilinguals indicated a higher level of proficiency for Chinese over English, and about equal or higher percentage of daily use for Chinese over English. Most had received more years of education in Chinese than in English (on average 9.7 and 4.1 years respectively).

\section{Between-group comparisons}

The three groups differed from each other in SES, parental education, and non-verbal intelligence. The differences in SES were significant between all three groups. Early Bilinguals had a lower average 
SES than both Late Bilinguals and Monolinguals, $F(1,97)=32.37$, $p<0.001$ and $F(1,97)=6.88, p=0.010$ respectively, while Late Bilinguals had a lower score than Monolinguals, $F(1,97)=8.09$, $p=0.005$. For parental education, the same trend across the three groups was observed as for SES, although only the comparison between Early Bilinguals and Monolinguals was statistically significant, $F(1,97)=12.02, p=0.001$. For non-verbal intelligence score, the Early Bilinguals had the highest average score and the Monolinguals the lowest, but only the comparison between those two groups was statistically significant, $F(1,97)=11.15, p=0.001$.

The comparisons between Early and Late Bilinguals on language characteristics revealed that Late Bilinguals had higher proficiency in L1 for each of the four language subskills (speaking, understanding, reading, and writing) than Early Bilinguals, smallest $t(64)=9.07, p<0.001$. Late Bilinguals also had greater percentage of use in L1 compared to Early Bilinguals, $F(1,64)=63.47$, $p<0.001$. On the other hand, Early Bilinguals indicated higher proficiency in L2 for each of the subskills than Late Bilinguals, smallest $t(64)=10.63, p<0.001$, and greater percentage of use in L2, $F(1,64)=63.74, p<0.001$. There were differences between the two groups, though not statistically significant, in the frequency of mixing, $F(1,64)=2.04, p=0.159$, and inhibiting, $F(1,64)=2.46$, $p=0.122$, where Late Bilinguals showed a greater average frequency in both (see Table 2).

\section{RESULTS}

\section{OVERALL RESULTS AVERAGED ACROSS THREE LANGUAGE GROUPS}

Trials with RTs faster than $200 \mathrm{~ms}$ or slower than $1200 \mathrm{~ms}$ (overall $1.8 \%$ ) and trials with errors were excluded from the RT analysis. The mean $\mathrm{RT}$ was $648 \mathrm{~ms}(\mathrm{SD}=112.6)$. The mean error rate $(\mathrm{ERR})$ yielded $12.6 \%(\mathrm{SD}=17.6)$. The mean RTs and ERRs broken by all conditions are presented in Table 3. The RT and ERR data were first analyzed by means of a 4 (cue condition: no cue, valid spatial, invalid spatial, center $) \times 2$ (flanker type: congruent, incongruent $) \times 2$ (visual field: left, right) ANOVA. The main effects of cue condition were significant both for RT, $F(3,297)=360.73, p<0.0001$, and ERR, $F(3,297)=85.11, p<0.0001$. The main effects of flanker type were also significant for RT, $F(1,99)=364.97, p<0.0001$, and for ERR, $F(1,99)=169.92, p<0.0001$. Importantly, the visual field asymmetry was found both for RT and ERR. Responses were $6 \mathrm{~ms}$ faster, $F(1,99)=4.77, p=0.03$, and $2.4 \%$ more accurate, $F(1,99)=17.22, p<0.001$, for targets presented in the left visual field (LVF) than in the right visual field (RVF). We also found significant cue $\times$ VF interaction for RT, $F(3,297)=4.24, p=0.006$, showing the largest asymmetry in the invalid cue condition, and flanker type $\times$ VF interaction for $\mathrm{ERR}, F(1,99)=22.31, p<0.001$, which showed the LVF advantage (5\%) in the incongruent condition and no asymmetry in the congruent condition. Description of other significant interactions obtained in the task goes beyond the research goals presented in this paper.

\section{Attentional networks}

The alerting effect was indexed by the difference between the center cue condition and no cue condition. Participants, averaged across three groups, responded $40 \mathrm{~ms}(\mathrm{SD}=28.7)$ faster on trials with a center cue than on trials with no cue, $t(99)=14.01, p<0.0001$, and made $2.7 \%(\mathrm{SD}=6.7)$ fewer errors, $t(99)=4.03, p<0.0001$. The orienting benefit effect was calculated by subtracting the RT or ERR of trials with a valid spatial cue from trials with a center cue. Participants took great benefit of a valid spatial cue, responding $67 \mathrm{~ms}(\mathrm{SD}=29.4)$ faster, $t(99)=22.81 ; p<0.0001$, and $4.6 \%$ $(\mathrm{SD}=5.4)$ more accurately, $t(99)=8.52 ; p<0.0001$, than on trials with a center cue. The orienting cost was calculated by subtracting the RT and ERR of trials with a center cue from trials with an invalid

Table 3 | Mean reaction times of correct responses and error rates for all conditions.

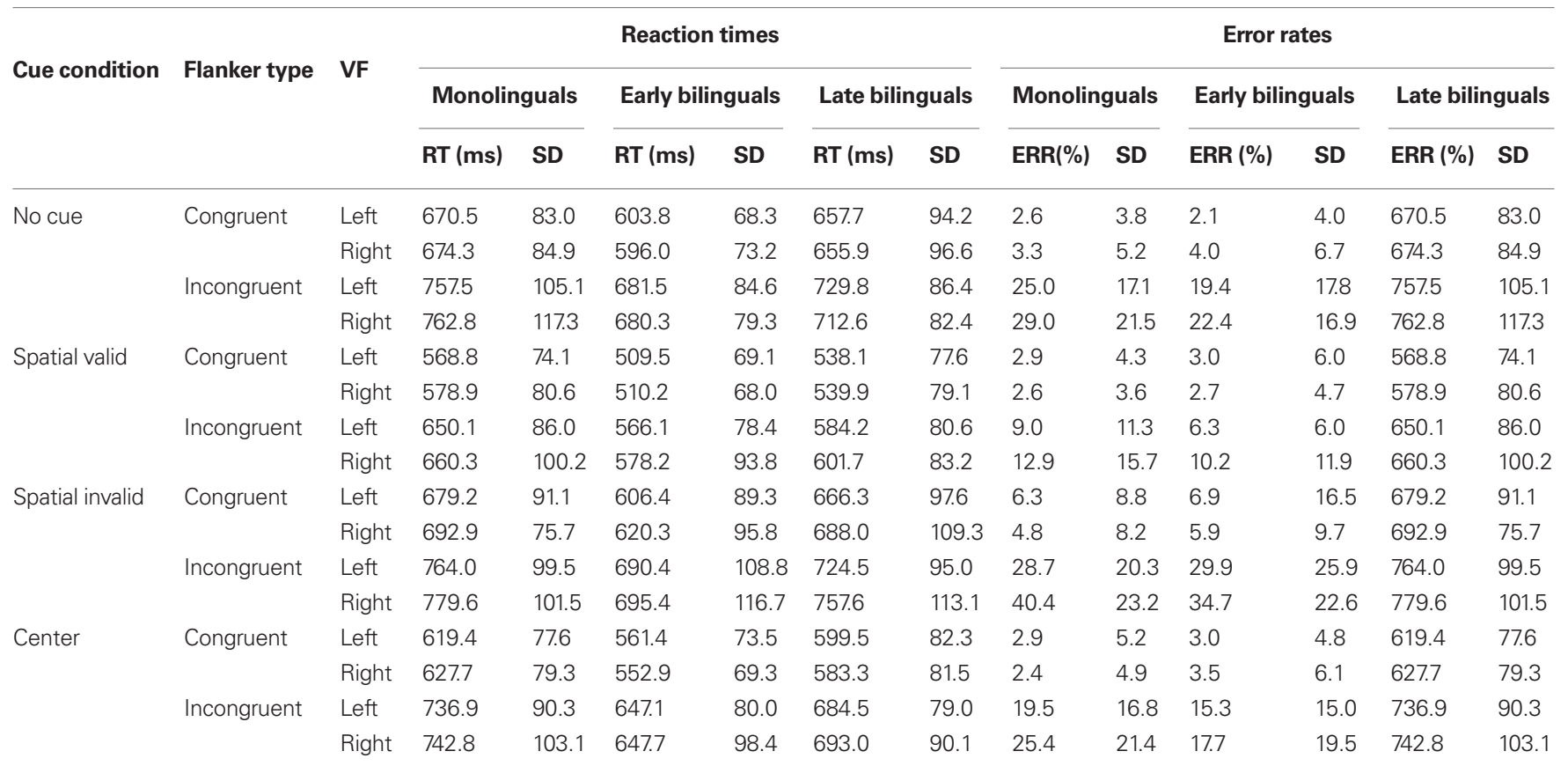


spatial cue. The cost of $55 \mathrm{~ms}$ on speed $(\mathrm{SD}=43.0)$ and $8.7 \%$ on accuracy $(\mathrm{SD}=9.8)$ were both significant, $t(99)=12.8, p<0.0001$, and $t(99)=8.8, p<0.0001$ respectively. The conflict effect, indexed by the difference between congruent and incongruent flanker conditions, yielded $80.7 \mathrm{~ms}(\mathrm{SD}=42.2)$ for $\mathrm{RT}, t(99)=19.10, p<0.0001$, and $15.9 \%(\mathrm{SD}=12.2)$ for ERR, $t(99)=13.03$; $p<0.0001$. All attention network indexes were similar for RT and ERR measurement; hence no speed-accuracy trade-off was observed.

\section{BETWEEN-GROUP COMPARISONS}

Because the groups differed on SES, parental education, and nonverbal intelligence, it is important to ensure that any differences between the groups in attentional functioning were not due to preexisting differences other than language background. Therefore, in all between-group analyses presented below, the parental education and Raven's non-verbal intelligence were included as covariates. SES was not controlled for as a third covariate due to its highly significant correlation with parental education $(r=0.51, p<0.001)$. Parental education was chosen over SES as the more objective measure of potential environmental influence since (a) SES had a moderate significant correlation with Raven's score $(r=-0.28$, $p=0.005)$, while parental education did not $(r=-0.05, p=0.61)$; and (b) some of the responses for parental occupation were too vague to properly classify and several of the parents were retired, making education level a more objective measure.

\section{Overall RT and ERR}

The results of ANCOVA showed that groups differed significantly on overall RT, $F(2,95)=4.59, p=0.012$, when controlling for parental education and intelligence. Early bilinguals responded the fastest $(609 \mathrm{~ms})$, monolinguals exhibited the longest time of reactions ( $685 \mathrm{~ms}$ ), while RT of late bilinguals fell in between $(651 \mathrm{~ms})$. Subsequent tests showed that the difference between monolinguals and early bilinguals was significant, $F(1,66)=11.15, p=0.001$, whereas the differences between monolinguals and late bilinguals, and between early and late bilinguals were not significant: $F(1,62)=1.76$, $p=0.19$, and $F(1,62)=2.35, p=0.13$, respectively. There was no significant group effect, $F<1$, on the overall ERR measure.

\section{Attentional networks}

Alerting. Monolinguals showed the smallest alerting affect (34.6 ms), the intermediate result was obtained for early bilingual group (38 ms), and late bilinguals obtained the largest effect (49 ms); see Figure 2 for the attentional network indexes in the three groups. This trend is in line with previous studies, in which bilingual advantage in the alerting network was observed (Costa et al., 2008; Marzecová et al., submitted for publication). However, the effect did not reach significance, $F(1,95)=2.19, p=0.12$. In the ERR analysis, the effect of group was not significant $(F<1)$.

Orienting. The three groups did not differ significantly in the orienting benefit effect, either in terms of RT, $F(2,95)=1.34, p=0.27$, or ERR, $F<1$. For the orienting cost, the late bilinguals showed the greatest cost $(69 \mathrm{~ms})$, while the early bilinguals and the monolinguals showed notably lesser costs (51 and $47 \mathrm{~ms}$, respectively). However, the trend did not reach significance, $F(2,95)=2.2$, $p=0.11$. To further investigate the effect of orienting cost in RT,

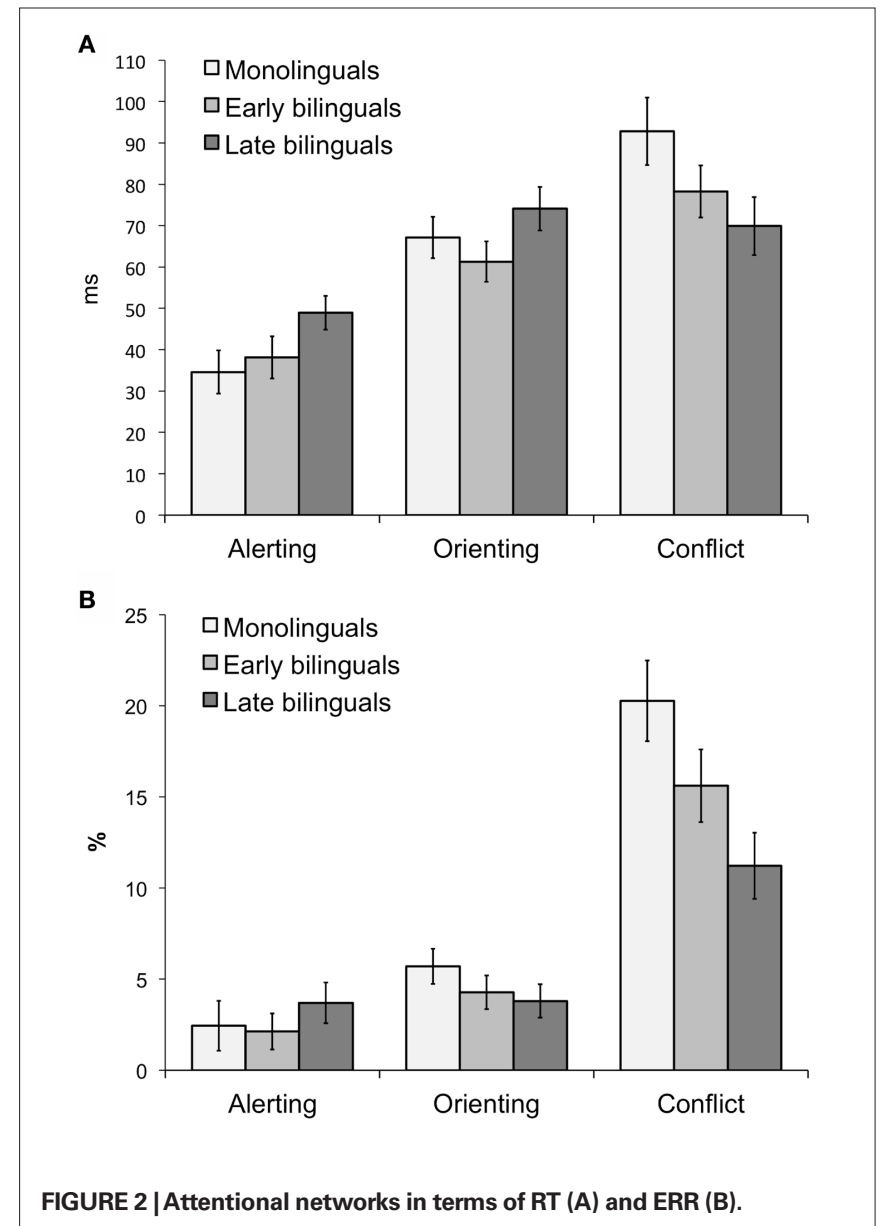

three between-group comparisons were carried out: monolinguals vs. early bilinguals, monolinguals vs. late bilinguals, and early vs. late bilinguals. The difference between late bilinguals and monolinguals was significant, $F(1,60)=4.55, p=0.037$, but the other two comparisons were not. Also, the ERR analysis for the three groups did not reveal any significant differences, $F(2,95)=1.09, p=0.34$.

Conflict. Crucially, the three groups differed in the efficiency of the executive network. The late bilinguals were found to be most efficient in resolution of conflict, with the cost of $69.8 \mathrm{~ms}$ in terms of RT and $11.2 \%$ in terms of ERR. The conflict cost in the early bilingual group was $78.2 \mathrm{~ms}$ for RT and $15.6 \%$ for ERR. The largest effect was observed in the monolingual group: participants in this group were $92.8 \mathrm{~ms}$ slower and $20.2 \%$ less accurate in the conflict than in the non-conflict trials. The main effect of group was significant for both RT, $F(2,95)=3.06, p=0.051$, and ERR, $F(2,95)=3.76$, $p=0.027$. To explore these effects, and to test specific hypotheses on differences between the three groups, separate analyses were carried out for three comparisons: monolinguals vs. early bilinguals, monolinguals vs. late bilinguals, and early vs. late bilinguals.

Monolinguals vs. early bilinguals. Compared to monolinguals, the early bilinguals showed significantly reduced conflict cost in RT (difference of $14.6 \mathrm{~ms}$ ) $\mathrm{F}(1,66)=4.74, \mathrm{p}=0.033$, but not in the accuracy of conflict resolution, $\mathrm{F}(1,66)=1.21, \mathrm{p}=0.27$. 
Monolinguals vs. late bilinguals. Late bilinguals were more efficient than monolinguals in the resolution of conflict, for both RT $(23 \mathrm{~ms})$, $F(1,60)=4.91, p=0.031$, and $\operatorname{ERR}(9 \%), F(1,60)=8.56, p=0.005$.

Early vs. late bilinguals. The lower conflict cost in terms of RT was observed for late bilinguals in comparison to the early bilinguals (69.8 vs. $78.2 \mathrm{~ms}$ ), although the effect was not significant, $F<1$. The magnitude of conflict in the ERR measure was significantly lower for late bilinguals ( 10 vs. $16.3 \%$ ), $F(1,62)=4.46, p=0.039$. Because the two language groups differed in self-rated proficiency for their two languages, we compared early and late bilinguals again, adding as covariates the L1 and L2 proficiency. When the L1 and L2 proficiency was controlled for, the between-group effects proved non-significant both for RT and ERR, Fs $<1$. However, because the two groups differed especially in reading and writing skills in Chinese (the early bilinguals reported very poor writing and reading skills in their L1 Chinese), for further analyses we calculated the index of L1-L2 balance in speaking and listening only. The index was a result of subtraction of the mean L2 proficiency in speaking and listening from the mean L1 proficiency. When this index was included as a covariate, the RT difference in conflict was still non-significant, $F<1$, while there was a strong trend indicating higher ERR in early than in late bilinguals, $F(1$, $61)=3.42, p=0.069$. A similar pattern of results was observed when an index of balance of daily use was used instead of the balance of proficiency. The "balance of use" was a subtraction of percentage of L2 use from percentage of L1 use. When this covariate was included, the differences for RTs remained non-significant, $F<1$, while for ERR the difference was again marginally significant, $F(1,61)=3.52, p=0.066$.

\section{Hemispheric asymmetry in monolinguals and bilinguals}

In order to investigate the functional hemispheric asymmetry in mono- and bilingual participants, we conducted ANCOVA with three within subject factors: cue condition (no cue, valid spatial, invalid spatial, center), flanker type (congruent, incongruent), and VF (left, right), and the group of participants as between subject factor. There were no significant interactions between VF and group, all $F s<1.5$, suggesting no between-group differences in the hemispheric asymmetry. However, based on previous research, we expected the reduced hemispheric asymmetry to be particularly apparent in the group of early bilinguals when compared to monolinguals. Therefore, to further explore the issue of hemispheric asymmetry, we carried out separate tests for the three following comparisons: monolinguals vs. early bilinguals, monolinguals vs. late bilinguals, and early vs. late bilinguals. While monolinguals responded $13 \mathrm{~ms}$ faster to the LVF than to the RVF targets, the early bilinguals did not exhibit such asymmetry ( $\mathrm{LVF}-\mathrm{RVF}=1 \mathrm{~ms})$; the pattern of lateralization in the three participant groups is presented in Figure 3. However, the interaction was only marginally significant, $F(1,66)=3.80, p=0.055$. The other comparisons between groups and visual fields were not significant.

\section{DISCUSSION}

The goal of the present study was to investigate the effects of managing two structurally distinct languages on the efficiency of attentional networks in early and late Chinese-English bilinguals. Additionally, we aimed to investigate the influence of early and late bilingualism on hemispheric asymmetries of attentional networks.

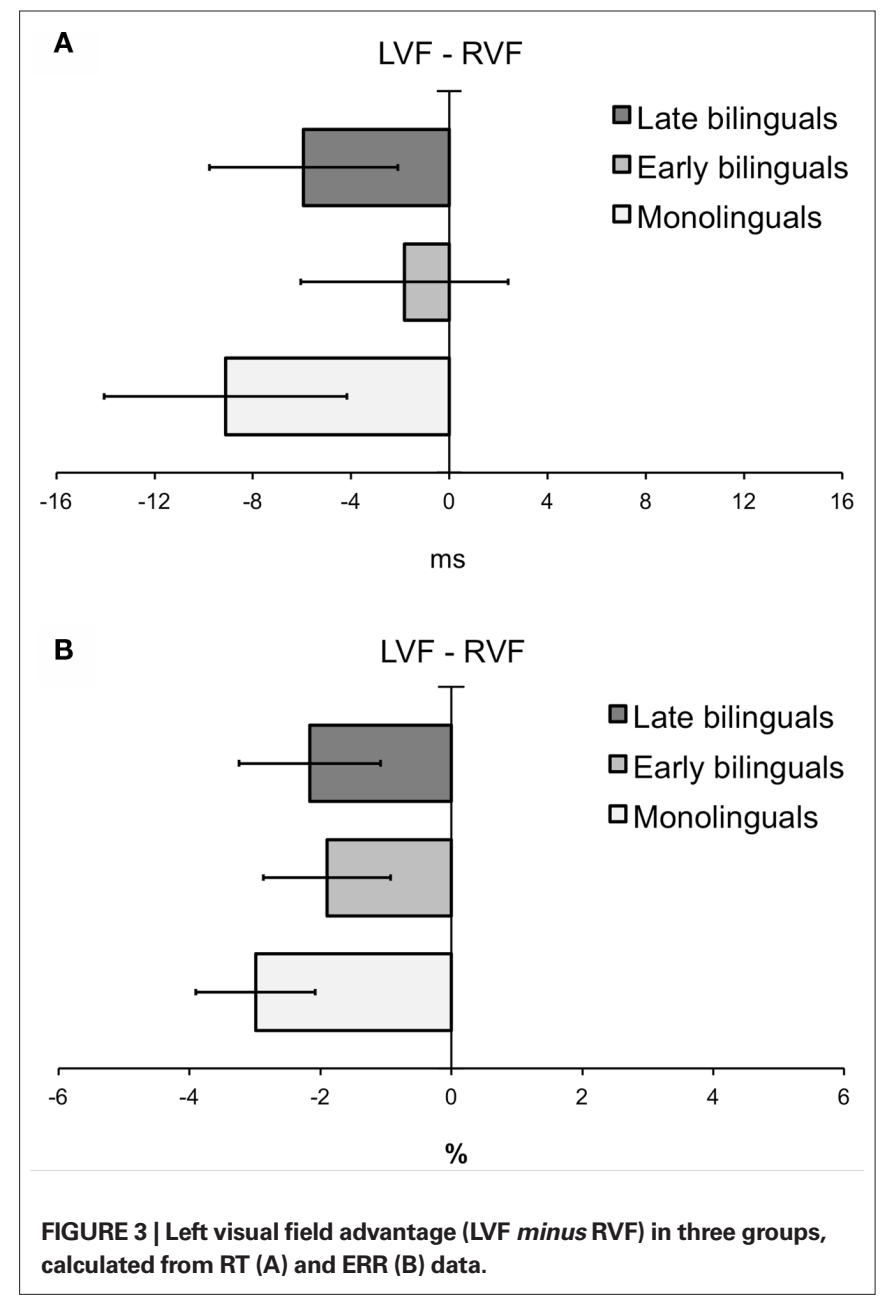

The overall pattern of results for the attentional networks across the three groups replicated findings from previous studies (Fan et al., 2002; Greene et al., 2008; see MacLeod et al., 2010, for a meta-analysis). Participants responded more quickly and made fewer errors when (a) there was a warning cue presented before the target stimuli (alerting network), (b) the spatial cue correctly indicated the location of the target (orienting network), and (c) flanking arrows pointed in the same direction as the target arrow (conflict/executive network). All these effects were robust and highly significant. The current variant of LANT was slightly more demanding than the previous ANT (Fan et al., 2002) and LANT (Greene et al., 2008), as revealed by the slower overall RT and higher ERR. It was presumed that greater demands on attention would circumvent the usually observed ceiling effect in accuracy, as well as improve the reliability of the measured effects (cf. Evert et al., 2003; Verleger et al., 2009; Asanowicz et al., submitted for publication). To this end, the eccentricity of the targets of the original LANT (Greene et al., 2008) was doubled. Presenting stimuli more peripherally was expected to decrease visual acuity and contrast sensitivity; hence, more attention would be needed for proper target discrimination (cf. Carrasco, 2011). 
Consistent with our predictions, the English monolinguals were less efficient in resolution of conflict than each of the two Chinese-English bilingual groups. Importantly, the effects were not attributable to differences in socioeconomic background or non-verbal intelligence, as these factors were statistically controlled for. The results are in line with previous studies that used the ANT to compare young adult bilinguals and monolinguals (Costa et al., 2008, 2009; Marzecová et al., submitted for publication) and extend their scope by including bilinguals who speak two languages that are distinct from each other (i.e., Chinese and English).

\section{THE DIFFERENTIAL IMPACT OF EARLY AND LATE BILINGUALISM ON EXECUTIVE CONTROL}

In the present study, both bilingual groups outperformed monolinguals. However, the difference between early bilinguals and monolinguals seemed to be qualitatively different from the difference between late bilinguals and monolinguals. On the one hand, the results for early bilinguals showed a reduced conflict cost in RT (but not in ERR) as well as an advantage in overall RT. On the other hand, there was an advantage for late bilinguals in conflict resolution both in terms of RT and ERR, without significant differences in overall RT or ERR.

In the vast majority of studies reporting a bilingual advantage in conflict resolution, the benefit has been present not just selectively for trials that require resolution of conflict, but also in the overall RT measure (see Table 1 for an overview). Such results have led researchers to propose that bilingualism may not only influence the efficiency of conflict resolution, but also another aspect of cognitive control, referred to as the "monitoring system," which evaluates the need to engage the conflict resolution mechanism (Bialystok et al., 2009; Costa et al., 2009). According to Costa et al. (2009), if the task at hand engages the monitoring system to a large extent, the advantage for bilinguals on overall RTs emerges. Costa et al. (2009) proposed two alternative ways in which the interplay between conflict resolution and monitoring processes might be explained. According to the first hypothesis, bilingualism may independently influence both monitoring and conflict resolution processes. According to the second hypothesis, the monitoring system may account for the observed bilingual advantage on both overall RT and conflict cost. The fact that the bilingual benefit in conflict resolution in most of the previous studies co-occurs with the overall RT benefit seems to support the latter claim (cf. Costa et al., 2009). However, recent findings by Marzecová et al. (submitted for publication) do not bear out this alternative and instead support the first hypothesis, according to which the two types of benefits might be dissociable. These authors reported the advantage for bilinguals over monolinguals in conflict resolution with no group differences on overall RT; moreover, their results were obtained in a condition in which high monitoring should have been involved (i.e., with a 50/50 proportion of congruent and incongruent trials; cf. Costa et al., 2009). In the present study, only early bilinguals outperformed monolinguals in overall RTs; the late bilinguals showed an advantage over monolinguals only in the conflict resolution per se. These results seem to indicate that specific bilingual experience may differentially influence the conflict resolution and/or monitoring systems. Let us consider some aspects of bilingual experience that may lead to enhancement of these particular cognitive processes.
The bilinguals tested in the two previous studies by Costa et al. $(2008,2009)$ were highly proficient and balanced early bilinguals. Since the bilingual advantage in overall RTs observed in those studies was not always accompanied by the reduced cost of conflict resolution, authors concluded that bilingualism primarily influences the monitoring system rather than the conflict resolution processes. In the present study, the bilingual advantage on overall RTs was observed only in combination with a reduced conflict cost for early bilinguals, whose L1 proficiency was rather limited. Although bilinguals from the studies by Costa et al. $(2008,2009)$ and the early bilinguals from the current study differed from each other in many aspects of language experience, they shared one common characteristic - the early age of acquisition. It seems plausible then to speculate that early, simultaneous consolidation of two language systems may bring about enhanced monitoring processes. However, it seems that not all early bilinguals show an advantage in monitoring (see Marzecová et al., submitted for publication), and that even bilinguals who acquired their two languages later in childhood (around age six) may exhibit such advantages (Emmorey et al., 2008). On the other hand, the late bilinguals in the present study, who were at the same time more balanced in their proficiency and use of their two languages (see Table 2), displayed the reduced conflict cost without any effects on overall performance. The results observed in the group of late bilinguals were similar to those reported in the study by Marzecová et al. (submitted for publication) on a group of early but moderately unbalanced bilinguals. Although bilinguals from the experiment conducted by Marzecová et al. (submitted for publication) and the late bilinguals from the present study differed in their age of L2 acquisition, they were similar with regard to balance and proficiency of the two languages. It seems that the common factor in their language experience - the moderate balance - might be responsible for the dissociation in the pattern of results: The lack of evidence for specific enhancement of monitoring processes (i.e., lack of advantage in overall RT) along with the clear advantage of a reduced conflict cost. Hence, although at this point it seems rather difficult to disentangle the factors that may lead to specific enhancement of cognitive processes in bilinguals, the present study shows the necessity of such an endeavor.

It seems important to note that alternative interpretations of overall RT advantage other than the monitoring account put forward by Costa et al. (2009) are plausible. The overall RT advantage may be equally interpreted as a measure of tonic alertness or vigilance (Roca et al., 2011). Therefore, the advantage of early bilinguals on overall performance may result from their greater vigilance. By this account, early bilinguals would be more focused on the task at hand and therefore more efficient in executing correct responses (cf. Marzecová et al., submitted for publication).

In additional analyses of the executive network efficiency, we compared the two bilingual groups. The late bilinguals showed reduced conflict cost in ERR when compared with early bilinguals. This result is consistent with our initial hypothesis that late bilinguals would show a greater advantage in conflict resolution than early bilinguals, since they may utilize the executive network to a greater extent in order to control the interference from L1 and to support processing of their less automatized L2. The bulk of evidence for a bilingual advantage in executive functions was based on research with bilinguals who used both languages regularly since 
early childhood, and were relatively proficient in both; that is, they were early balanced bilinguals (e.g., Carlson and Meltzoff, 2008; Costa et al., 2008, 2009; Hernandez et al., 2010; see also Bialystok, 2009, for a review). Because in most of these studies, the experiential factors were correlated with each other, it was impossible to disentangle the relative importance of each of them. The present study indicates clearly, that early L2 acquisition is not essential for the enhancement of conflict resolution processes, although it may play a part in the emergence of efficient monitoring processes.

Although in the present study, neither the early nor the late bilingual group could be regarded as perfectly balanced (considering the self-ratings of proficiency and percentage of use in L1 and L2 reported in Table 2), the early bilinguals were significantly less balanced than the late group. When the balance of proficiency (in terms of speaking and listening comprehension) or balance of use was controlled for, the differences between early and late bilinguals became markedly reduced. Thus, the present finding showing greater enhancement in conflict resolution for the late bilingual group seems to be in line with previous studies showing greater efficiency of executive control in balanced bilinguals (Carlson and Meltzoff, 2008; Luk and Bialystok, 2008). Furthermore, the advantage over monolinguals observed for the early bilingual group adds to the existing literature in providing evidence that enhancement of executive control is plausible for bilinguals who are far from being balanced. Taken together, the results from the present study suggest that the degree of balance between the bilinguals' two languages may have a greater impact on conflict resolution than the age of onset of bilingualism, but that the age of L2 acquisition may play an important role in mediating the monitoring advantage.

\section{ALERTING NETWORK}

Regarding the efficiency of the alerting, there was a trend for late bilinguals to exhibit greater benefit from the alerting cue than did the other two groups. Such a trend accords with previous studies in which a larger alerting effect was found for bilinguals compared to monolinguals (Costa et al., 2008; Marzecová et al., submitted for publication). There is no apparent explanation for the lack of significant group differences in alerting, apart from the concern of a methodological nature. It has been reported that the reliability of the alerting index as measured by the ANT is considerably lower than indexes of orienting and executive networks (MacLeod et al., 2010). This especially holds true for the LANT designed by Greene et al. (2008), in which the reliability of the alerting index is even lower than in the ANT. Hence, with regard to the alerting network, the experimental design might not be have been sensitive enough to capture the potentially small between-group differences, especially using a participant sample that is smaller relative to the Costa et al. (2008) study $(n=200)$.

At present not enough experimental evidence is available to provide an account of the mechanisms underlying the effects of bilingualism on the alerting network (cf. Costa et al., 2008). It is speculated that, unlike Chinese-English bilinguals in the present study, bilinguals with two structurally similar language sets (e.g., Catalan-Spanish) may need to achieve and maintain a higher state of alertness in monitoring and switching between their languages, thus gaining significant enhancement in the alerting network. Furthermore, since the central cue was always predictive of the time of target presentation, the alerting index may be seen as a combination of two processes: alertness and response preparation based on temporal expectancy. Temporal preparation has been shown to enhance not only perceptual processing, but also motor processing, thus leading to faster RTs as well as higher accuracy (Correa et al., 2005). Moreover, such an anticipatory process has been shown to enhance controlled stimulus-response selection (Correa et al., 2009). The trend for late bilinguals to show higher alerting may therefore suggest an enhanced efficiency of response anticipation mechanisms (Marzecová et al., submitted for publication), which are known to be supported by the executive control network (cf. Fan et al., 2007; Correa et al., 2009).

\section{ORIENTING NETWORK}

In relation to the orienting network, the absence of between-group differences in orienting benefit is consistent with previous studies (Costa et al., 2008, 2009). However, in the current study, the late bilinguals showed significantly greater orienting cost compared to monolinguals, i.e., they were slower to reorient attention to a target occurring in an invalidly cued location. It has been shown that in tasks with highly predictive spatial cues (as was the case in the current study), the orienting cost is associated with deactivation of the temporo-parietal junction (TPJ; Doricchi et al., 2010) - the structure that regulates reorienting of attention to uncued locations (Corbetta et al., 2008). The inhibition of TPJ seems to lead to greater filtering of stimuli occurring in the uncued location (Doricchi et al., 2010; Lasaponara et al., 2011). Therefore, the observed effect may indicate that late bilinguals have a greater capacity to inhibit stimuli that occur in an invalid location, which helps them use the predictive cue more efficiently by filtering out the uncued stimuli in the anticipatory period.

\section{HEMISPHERIC ASYMMETRY}

The LVF advantage was observed in both overall RT and ERR measures across all three groups, generally suggesting right hemisphere superiority in attentional processing (cf. Heilman, 1995; Mesulam, 1999), as assessed by behavioral measures of attentional networks. Additionally, the RT in the invalid spatial cue condition indicated right hemisphere specialization in reorienting of attention to targets occurring outside the current focus of attention. This is consistent with the neuroanatomical model of orienting networks proposed by Corbetta and Shulman (2002). The accuracy measure in the incongruent flanker condition seems to point to dominance of the right executive network in conflict resolution, which accords with several behavioral and imaging studies (Hazeltine et al., 2003; Aron et al., 2004; Asanowicz et al., submitted for publication; but see Fan et al., 2003). For the alerting effect, as in earlier LANT studies (Greene et al., 2008; Poynter et al., 2010), we did not observe any VF affects.

In line with our hypothesis, the comparisons of VF effects for overall RT in monolingual and early bilingual groups revealed a strong trend toward a reduced LVF advantage in early bilinguals. Additionally, the comparison of VF asymmetry for overall RT between monolinguals and late bilinguals showed no significant difference. These results are consistent with our predictions and with previous findings suggesting that bilinguals, particularly those who have acquired L2 at an early age, display reduced right hemisphere 
dominance for non-linguistic cognitive processing. It has been put forward that bilinguals who learned their second language before age six show bilateral, rather than left hemisphere dominant, cerebral organization of language as a result of early use of multiple languages, as the brain is undergoing extensive neuron wiring and synaptic changes from age three to six (Peng and Wang, 2011). It is plausible, then, that such cortical changes at an early age may have similar effects in the cerebral organization in non-linguistic domains of cognitive processing. In the study by Marzecová et al. (submitted for publication), in which attentional functioning was examined using the LANT task, bilinguals displayed reduced hemispheric asymmetry in the executive network as compared to monolinguals. In addition, Hausmann et al. (2004) observed that bilinguals displayed reduced right hemisphere involvement relative to monolinguals in face discrimination, a process that is typically more dominant in the right hemisphere. Furthermore, these results are in accordance with studies on language processing which show reduced hemispheric asymmetry in bilinguals (see Hull and Vaid, 2007, for a meta-analysis). However, no other differences in lateralization between monolinguals and bilinguals were observed in the current study. In particular, we did not observe the reduced asymmetry of executive network in early bilinguals, which was reported by Marzecová et al. (submitted for publication). There were also no group differences in lateralization for the ERR measure; all three groups of participants had a similar, small but reliable, LVF advantage in performance accuracy. It is important to note that these results should be interpreted with caution, since there have been arguments made that behavioral laterality measures do not provide a reliable measurement of hemispheric asymmetry (cf. Paradis, 2009).

In addition, several methodological factors might have led to the pattern of results that are much less straightforward than those obtained by Marzecová et al. (submitted for publication). The LANT task used in the current study was based to a large extent on the procedure proposed by Greene et al. (2008), in which generally no asymmetries were observed. Thus, the fact that some VF effects were obtained, and were even quite consistent between groups, is noteworthy. Considering that (1) effects of attentional asymmetries are generally small and may be affected by many factors (cf. Jewell and McCourt, 2000); (2) between-group differences in attentional asymmetries must therefore be even smaller and, thus, we need even more statistical power; (3) behavioral measures of hemispheric asymmetries are indirect and inherently noisy (Zaidel, 1995), we can conclude that using an almost four times

\section{REFERENCES}

Abutalebi, J. (2008). Neural processing of second language representation and control. Acta Psychol. (Amst) 128, 466-478.

Abutalebi, J., and Green, D. W. (2007). Bilingual language production: the neurocognition of language representation and control. J. Neurolinguistics 20, 242-275.

Andreou, G., and Karapetsas, A. (2001). Hemispheric asymmetries of visual ERPs in left-handed bilinguals. Cogn. Brain Res. 12, 333-335.

larger sample than Greene et al. (2008) increased statistical power, which in turn allowed us to observe the asymmetries. However, the power might still be insufficient.

To summarize, the results seem to be consistent with the hypothesis according to which early bilingualism reduces hemispheric asymmetry of attentional networks. However, the results are far from conclusive and more research is needed to explore this issue in greater depth. Of particular note, the question of the possible modulating effects of age of L2 acquisition on the interhemispheric organization of cognitive functions remains open.

\section{CONCLUSION}

The present study demonstrates that continual practice in monitoring and switching between two language systems can lead to the enhanced executive control due to involvement of inhibitory control processes that are required to select and produce the intended language (Green, 1998). This seems to hold true regardless of the age at which bilinguals have acquired their second language, and regardless of the similarity between the two languages. Furthermore, the benefit from the continual practice in keeping two languages apart appears to be present even for bilinguals who are strongly dominant in one of their languages, although late and more balanced bilinguals appear to show a greater enhancement in conflict resolution. The results also suggest that the age of L2 acquisition may mediate the impact of bilingualism on monitoring processes; in the current study the bilingual advantage in overall RTs was only observed in the group of early bilinguals. Such a result seems to indicate that early (and continuous) contact with two languages may be critical for the monitoring advantage to emerge. Therefore, the results clearly suggest a pattern of dissociation in the influences of bilingual experience on conflict monitoring and conflict resolution processes. Further research should aim at a scrupulous disentanglement of specific factors related to language experience, which might differentially influence cognitive control processes in bilinguals.

\section{ACKNOWLEDGMENTS}

This research was supported by a subsidy from Foundation for Polish Science and by a Group of Eight European Fellowship to Zofia Wodniecka. It was also supported by a grant from the Australian Research Council awarded to Marcus Taft. The authors wish to thank Lidija Krebs-Lazendic for technical assistance with the study and the Reviewers for their invaluable comments and suggestions.

Bialystok, E. (2009). Bilingualism: the good, the bad, and the indifferent. Biling. (Camb. Engl.) 12, 3-11.

Bialystok, E. (2010). Global-local and trail-making tasks by monolingual and bilingual children: beyond inhibition. Dev. Psychol. 46, 93-105.

Bialystok, E., Craik, F., and Luk, G. (2008). Cognitive control and lexical access in younger and older bilinguals. $J$. Exp. Psychol. Learn. Mem. Cogn. 34 859-873.

Bialystok, E., Craik, F. I. M., Grady, C., Chau, W., Ishii, R., Gunji, A., and
Pantev, C. (2005a). Effect of bilingualism on cognitive control in the Simon task: evidence from MEG. Neuroimage 24, 40-49.

Bialystok, E., Martin, M. M., and Viswanathan, M. (2005b). Bilingualism across the lifespan: the rise and fall of inhibitory control. Int J. Bilingualism 9, 103-119.

Bialystok,E.,Craik, F.I.M., Green,D.W., and Gollan, T. H. (2009). Bilingual minds. Psychol. Sci. Public Interest 10, 89-129.

Bialystok, E., Craik, F. I. M., Klein, R., and Viswanathan,M. (2004). Bilingualism, 
aging, and cognitive control: evidence from the Simon task. Psychol. Aging 19, 290-303.

Bialystok, E., Craik, F. I. M., and Ryan, J. (2006). Executive control in a modified antisaccade task: effects of aging and bilingualism. J. Exp. Psychol. Learn. Mem. Cogn. 32, 1341-1352.

Bialystok, E., and Martin, M. M. (2004). Attention and inhibition in bilingual children: evidence from the dimensional change card sort task. Dev. Sci. 7, 325-339.

Bialystok, E., and Viswanathan, M. (2009). Components of executive control with advantages for bilingual children in two cultures. Cognition 112, 494-500.

Carlson, S. M., and Meltzoff,A. N. (2008). Bilingual experience and executive functioning in young children. Dev. Sci. 11, 282-298.

Carrasco,M. (2011).Visual attention. Vision Res. doi: 10.1016/j.visres.2011.04.012

Chee, M. W. L., Tan, E. W. L., and Thiel, T. (1999). Mandarin and English single word processing studied with functional magnetic resonance imaging. J. Neurosci. 19, 3050-3056.

Colzato, L. S., Bajo, M. T., van den Wildenberg, W., Paolieri, D., Nieuwenhuis, S., La Heij, W., and Hommel, B. (2008). How does bilingualism improve executive control? A comparison of active and reactive inhibition mechanisms. J. Exp. Psychol. Learn. Mem. Cogn. 34, 302-312.

Corbetta, M., Patel, G., and Shulman, G. L. (2008). The reorienting system of the human brain: from environment to theory of mind. Neuron 58, 306-324.

Corbetta, M., and Shulman, G. L. (2002). Control of goal-directed and stimulusdriven attention in the brain. Nat. Rev. Neurosci. 3, 201-215.

Correa, A., Lupiáñez, J., and Tudela, P. (2005).Attentional preparation based on temporal expectancy modulates processing at the perceptual level. Psychon. Bull. Rev. 12, 328-334

Correa, A., Rao, A., and Nobre, A. C. (2009). Anticipating conflict facilitates controlled stimulus-response selection. J. Cogn. Neurosci. 21, 1461-1472.

Costa, A., Hernandez, M., Costa-Faidella, J., and Sebastian-Galles, N. (2009). On the bilingual advantage in conflict processing: now you see it, now you don't. Cognition 113, 135-149.

Costa, A., Hernandez, M., and SebastianGalles, N. (2008). Bilingualism aids conflict resolution: evidence from the ANT task. Cognition 106, 59-86.

Dehaene, S., Dupoux, E., Mehler, J., Cohen, L., Paulesu, E., Perani, D., and Le Bihan, D. (1997). Anatomical variability in the cortical representation of first and second language. Neuroreport 8, 3809-3815.
Doricchi, F., Macci, E., Silvetti, M., and Macaluso, E. (2010). Neural correlates of the spatial and expectancy components of endogenous and stimulus-driven orienting of attention in the posner task. Cereb. Cortex 20, 1574-1585.

Dunn, A. L., and Fox Tree, J. E. (2009). A quick, gradient Bilingual Dominance Scale. Biling. (Camb. Engl.) 12, 273-289.

Emmorey, K., Luk, G., Pyers, J. E., and Bialystock, E. (2008). The source of enhanced cognitive control in bilinguals: evidence from bimodal bilinguals. Psychol. Sci. 19, 1201-1206.

Eriksen, B. A., and Eriksen, C. W. (1974). Effects of noise letters upon the identification of a target letter in a nonsearch task. Percept. Psychophys. 16, 143-149.

Evert, D. L., McGlinchey-Berroth, R., Verfaellie, M., and Milberg, W. P. (2003). Hemispheric asymmetries for selective attention apparent only with increased task demands in healthy participants. Brain Cogn. $53,34-41$.

Fan, J., Flombaum, J., McCandliss, B., Thomas, K., and Posner, M. (2003). Cognitive and brain consequences of conflict. Neuroimage 18, 42-57.

Fan, J., Kolster, R., Ghajar, J., Suh, M., Knight, R. T., Sarkar, R., and McCandliss, B. D. (2007). Response anticipation and response conflict: an event-related potential and functional magnetic resonance imaging study. J. Neurosci. 27, 2272-2282.

Fan, J., McCandliss, B. D., Sommer, T., Raz, A., and Posner, M. I. (2002). Testing the efficiency and independence of attentional networks. J. Cogn. Neurosci. 14, 340-347.

Festman, J., Rodriguez-Fornells, A., and Munte, T. F. (2010). Individual differences in control of language interference in late bilinguals are mainly related to general executive abilities. Behav. Brain Funct. 6, 5.

Forster, K. I., and Forster, J. C. (2003). DMDX: a windows display program with millisecond accuracy. Behav. Res. Methods Instrum. Comput.35, 116-124. Goetz, P. J. (2003). The effects of bilingualism on theory of mind development. Biling. (Camb. Engl.) 6, 1-15.

Green, D. W. (1998). Mental control of the bilingual lexico-semantic system. Biling. (Camb. Engl.) 1, 67-81.

Greene, D. J., Barnea, A., Herzberg, K., Rassis, A., Neta, M., Raz,A., and Zaidel, E. (2008). Measuring attention in the hemispheres: the lateralized attention network test (LANT). Brain Cogn. 66, 21-31.

Hausmann, M., Durmusoglu, G., Yazgan, Y., and Gunturkun, O. (2004).Evidence for reduced hemispheric asymmetries in non-verbal functions in bilinguals. J. Neurolinguistics 17, 285-299.

Hazeltine, E., Bunge, S. A., Scanlon, M. D., and Gabrieli, J. D. (2003). Materialdependent and material-independent selection processes in the frontal and parietal lobes: an event-related fMRI investigation of response competition. Neuropsychologia 41, 1208-1217.

Heilman, K. M. (1995). "Attentional asymmetries," in Brain Asymmetry, eds R. J. Davidson and K. Hugdahl (Cambridge, MA: The MIT Press), 217-234.

Hernandez,A. E., Li, P., and MacWhinney, B. (2005). The emergence of competing modules in bilingualism. Trend Cogn. Sci. (Regul. Ed.) 9, 220-225.

Hernandez, A. E., and Meschyan, G. (2006). Executive function is necessary to enhance lexical processing in a less proficient L2: evidence from $\mathrm{AMRI}$ during picture naming. Biling. (Camb Engl.) 9, 177-188.

Hernandez, M., Costa, A., Fuentes, L. J., Vivas, A. B., and Sebastian-Galles, N (2010). The impact of bilingualism on the executive control and orienting networks of attention. Biling. (Camb. Engl.) 13, 315-325.

Hull, R., and Vaid, J. (2006). Laterality and language experience. Laterality 11, 436-464.

Hull, R., and Vaid, J. (2007). Bilingual language lateralization: a metaanalytic tale of two hemispheres. Neuropsychologia 45, 1987-2008.

Jewell, G., and McCourt, M. E. (2000). Pseudoneglect: a review and metaanalysis of performance factors in line bisection tasks. Neuropsychologia 38, 93-110.

Kovelman, I., Baker, S. A., and Petitto, L. A. (2008). Bilingual and monolingual brains compared: an fMRI investigation of syntactic processing and a possible "neural signature" of bilingualism. J. Cogn. Neurosci. 20, 153-169.

Kroll, J. F. (2008). Juggling two languages in one mind. Psychol. Sci. Agenda 22, 3-7.

Kroll, J. F. (2009). The consequences of bilingualism for the mind and the brain. Psychol. Sci. Public Interest 10 i-ii.

Lasaponara, S., Chica, A. B., Lecce, F. Lupiáñez, J., and Doricchi, F. (2011). ERP evidence for selective drop in attentional costs in uncertain environments: Challenging a purely premotor account of covert orienting of attention. Neuropsychologia. doi: 10.1016/j. neuropsychologia.2011.05.012

Li, P., Sepanski, S., and Zhao, X. (2006). Language history questionnaire: a web-based interface for bilingual research. Behav. Res. Methods 38, 202-210.

Luk, G., Anderson, J. A. E., Craik, F. I. M., Grady, C., and Bialystok, E. (2010). Distinct neural correlates for two types of inhibition in bilinguals: response inhibition versus interference suppression. Brain Cogn. 74, 347-357.

Luk, G., and Bialystok, E. (2008). Common and distinct cognitive bases for reading in English-Cantonese bilinguals. Appl. Psycholinguist. 29, 269-289.

MacLeod, J. W., Lawrence, M. A., McConnell, M. M., Eskes, G. A., Klein, R. M., and Shore, D. I. (2010). Appraising the ANT: psychometric and theoretical considerations of the attention network test. Neuropsychology 24, 637-651.

Marks, G. N., McMillan, J., Jones, F. L., and Ainley, J. (2000). The Measurement of Socioeconomic Status for the Reporting of Nationally Comparable Outcomes of Schooling. Australian Council for Educational Research Draft Report. Available at: http://www.curriculum. edu.au/verve/_resources/socioeconomicstatus_file.pdf

Martin-Rhee, M. M., and Bialystok, E. (2008). The development of two types of inhibitory control in monolingual and bilingual children. Biling. (Camb. Engl.)11, 81-93.

McMillan, J. (2010). Occupation-based conceptualisations of socioeconomic status. Paper Presented at the Socioeconomic Status and Australian Higher Education Students Symposium, University of Technology, Sydney.

McMillan, J., Beavis, A., and Jones, F. L. (2009). The AUSEI06: a new socioeconomic index for Australia. J. Sociol. 45 123-149.

Mesulam, M. M. (1999). Spatial attention and neglect: parietal, frontal and cingulate contributions to the mental representation and attentional targeting of salient extrapersonal events. Philos. Trans. R. Soc. Lond. B Biol. Sci. 354 1325-1346.

Moreno, S., Bialystok, E., Wodniecka, Z., and Alain, C. (2010). Conflict resolution in sentence processing by bilinguals. J. Neurolinguistics 23, 564-579.

Morton, J. B., and Harper, S. N. (2007). What did Simon say? Revisiting the bilingual advantage. Dev. Sci. 10 , 719-726.

Oldfield, R. C. (1971). The assessment and analysis of handedness: the Edinburgh inventory. Neuropsychologia 9, 97-113.

Paradis, M. (2009). Procedural and Declarative Determinants of Second Languages. Amsterdam: John Benjamins.

Peng, G., and Wang, W. S. (2011). Hemispherelateralization is influenced by bilingual status and composition 
of words. Neuropsychologia 49, 1981-1986.

Posner, M. I. (1980). Orienting of attention. Q. J. Exp. Psychol. 32, 3-25.

Posner, M. I. (2008). Measuring alertness. Ann. N. Y. Acad. Sci. 1129, 193-199.

Posner, M. I., and Fan, J. (2008). "Attention as an organ system," in Topics in Integrative Neuroscience: From Cells to Cognition, ed. J. R. Pomerantz (New York: Cambridge University Press), 31-61.

Posner, M. I., and Rothbart, M. K. (2007). Research on attention networks as a model for the integration of psychological science. Annu. Rev. Psychol. 58, 1-23.

Poynter, W., Ingram, P., and Minor, S. (2010). Visual field asymmetries in attention vary with self-reported attention deficits. Brain Cogn. 72, 355-361.

Prior, A., and MacWhinney, B. (2010). A bilingual advantage in task switching. Biling. (Camb. Engl.) 13, 253-262.

Raven, J., Raven, J. C., and Court, J. H. (1998). Manual for Raven's Progressive Matrices and Vocabulary Scales. Section 4: The Advanced
Progressive Matrices. Oxford: Oxford Psychologists Press.

Raz, A., and Buhle, J. (2006). Typologies of attentional networks. Nat. Rev Neurosci. 7, 367-379.

Roca, J., Castro, C., López-Ramóna, M. F., and Lupiáñez, J. (2011). Measuring vigilance while assessing the functioning of the three attentional networks: the anti-vigilance task. J. Neurosci. Methods 198, 312-324.

Soveri, A., Laine, M., Hamalainen, H., and Hugdahl, K. (2010). Bilingual advantage in attentional control: evidence from the forced-attention dichotic listening paradigm. Biling. (Camb. Engl.) 14, 371-378.

Stevens, C., Lauinger, B., and Neville, H. (2009). Differences in the neural mechanisms of selective attention in children from different socioeconomic backgrounds: an event-related brain potential study. Dev. Sci. 12, 634-646.

Tan, L. H., Spinks, J. A., Feng, C.-M., Siok, W. T., Perfetti, C. A., Xiong, J., and Gao, J.-H. (2003). Neural systems of second language reading are shaped by native language. Hum. Brain Mapp. $18,158-166$. van Heuven, W. J. B., Schriefers, H., Dijkstra, T., and Hagoort, P. (2008). Language conflict in the bilingual brain. Cereb. Cortex 18, 2706-2716.

Verleger, R., Sprenger, A., Gebauer, S., Fritzmannova, M., Friedrich, M., Kraft, S., and Jaśkowski, P. (2009). On why left events are the right ones: neural mechanisms underlying the left-hemifield advantage in rapid serial visual presentation. J. Cogn. Neurosci. $21,474-488$.

Wartenburger, I., Heekeren, H. R., Abutalebi, J., Cappa, S. F., Villringer, A., and Perani, D. (2003). Early setting of grammatical processing in the bilingual brain. Neuron 37, 159-170.

Wodniecka, Z., Craik, F. I. M., Luo, L., and Bialystok,E. (2010).Does bilingualism help memory? Competing effects of verbal ability and executive control. Int. J. Biling. Educ. Biling. 13, 575-595.

Ye, Z., and Zhou, X. (2009). Executive control in language processing. Neurosci. Biobehav. Rev. 33, 1168-1177.

Zaidel, E. (1995). "Interhemispheric transfer in the split brain: longterm status following complete cerebral commissurotomy," in Brain
Asymmetry, eds R. J. Davidson and K. Hugdahl (Cambridge, MA: The MIT Press), 491-532.

Conflict of Interest Statement: The authors declare that the research was conducted in the absence of any commercial or financial relationships that could be construed as a potential conflict of interest.

Received: 21 March 2011; accepted: 28 May 2011; published online: 10 June 2011.

Citation: Tao L, Marzecová A, Taft M, Asanowicz D and Wodniecka Z (2011) The efficiency of attentional networks in early and late bilinguals: the role of age of acquisition. Front. Psychology 2:123. doi: 10.3389/fpsyg.2011.00123

This article was submitted to Frontiers in Cognition, a specialty of Frontiers in Psychology.

Copyright $\odot 2011$ Tao, Marzecová, Taft, Asanowicz and Wodniecka. This is an openaccess article subject to a non-exclusive license between the authors and Frontiers Media $S A$, which permits use, distribution and reproduction in other forums, provided the original authors and source are credited and other Frontiers conditions are complied with. 